\title{
Climate Change and World Energy
}

Alan McDonald (mcdonald@iiasa.ac.at)

\section{Approved by}

Leo Schrattenholzer

Project Leader, Environmentally Compatible Energy Strategies (ECS) Project

February 14, 2000 


\section{Contents}

1 INTRODUCTION

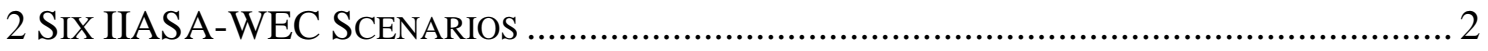

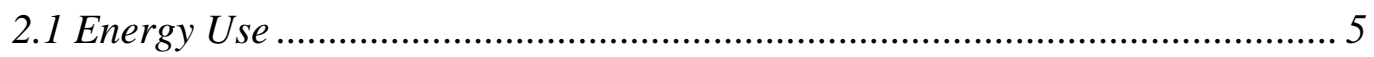

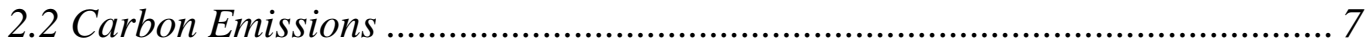

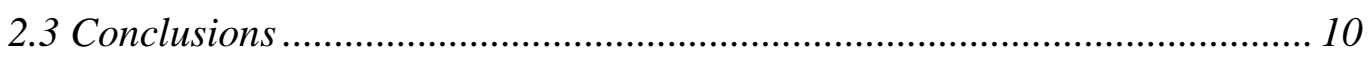

3 TeChNological PRogress AND Non-Fossil ENERgy SOURCES ................................. 11

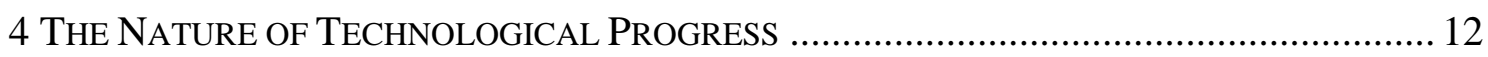

4.1 "Let a Thousand Flowers Bloom" ........................................................ 13

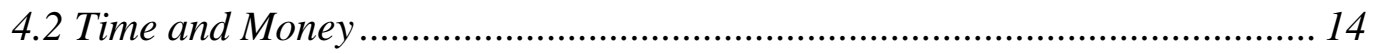

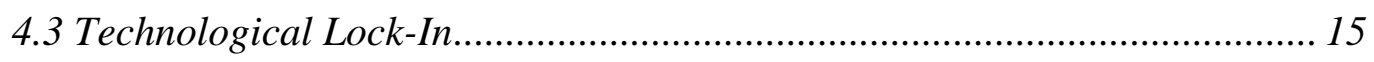

5 THE Kyoto Protocol AND INCENTIVES FoR TeChNOLOGICAL PROGRESS ................... 15

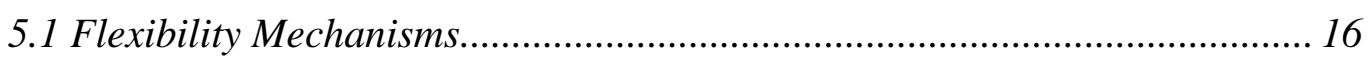

5.2 Participation of Developing Countries ........................................................ 23

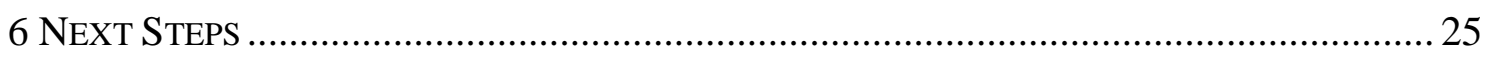

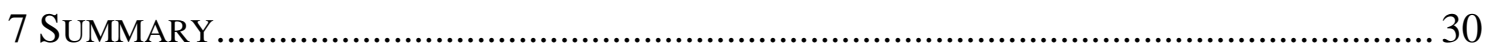

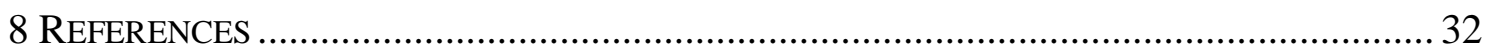




\begin{abstract}
This Interim Report first appeared as a chapter in Climate Change Socioeconomic Dimensions and Consequences of Mitigation Measures (Pekka Pirilä, Editor; publisher Oy EDITA AB, Helsinki, 2000). It is reprinted here, with permission, with minor revisions. Preceding chapters in the book discuss possible adverse consequences of climate change. This chapter starts by assuming that the possibility of such adverse consequences justifies action to limit climate change. Its purpose is then twofold. First, it summarizes the state of the art in modeling long-term greenhouse gas emissions from energy use, and extracts lessons for international (and national) efforts to limit emissions. Two such lessons are emphasized -- the importance of technological progress to reduce the world's energy intensity, and the importance of shifting from fossil to non-fossil fuels as our primary energy sources. Given these basic objectives, this chapter next addresses "burden sharing" -- the question of how the burden of limiting emissions ought to be shared among countries, particularly between rich and poor. The chapter does not advocate any particular burden sharing formula; indeed it argues that debates over formulas may generate more heat than light. Instead the chapter emphasizes efforts to implement and expand emission trading, particularly with developing countries, which are expected to have large opportunities for low-cost emission reductions. Not only will effective trading lead to efficient reductions, it could well represent large revenues for developing countries -- revenues that the rich developed countries could well be more than happy to pay.
\end{abstract}




\title{
Climate Change and World Energy
}

\author{
Alan McDonald
}

\section{Introduction}

This chapter assumes that the potential dangers outlined in previous chapters make a persuasive case for limiting possible global warming. The chapter starts by reviewing scenarios of long-term global energy use, the prime source of anthropogenic greenhouse gas (GHG) emissions, to see what they suggest as essential pieces of a successful mitigation strategy. Two important generalizations emerge. These are the importance of technological progress to reduce the world's energy intensity if GHG concentrations are to be stabilized, and the importance of shifting from fossil to non-fossil fuels as our primary energy sources. The chapter then examines current issues and proposals within the framework of the Kyoto Protocol and the UNFCCC ${ }^{1}$ negotiation process in light of these two necessary conditions for GHG stabilization. The chapter's final section attempts to outline a plausible generic strategy at a national level that incorporates the principal lessons of the global perspective within the constraints of the existing political debate.

The analysis of scenarios describing possible long-term emissions of greenhouse gases and their possible impacts has become a big business. Morita and Lee (1998) have assembled a selective database that still contains over 400 such scenarios. These 400 -plus scenarios show tremendous variation in their particulars. Some of this reflects the tastes and preferences of the scenario builders and the different capabilities of the models they use. But most of it reflects the very real uncertainty in nearly every facet of global warming that researchers can conceive of studying -- population growth, economic growth, political changes, technological developments, energy resources, land needs, human diets, ecosystem responses, atmospheric chemistry, and so on. As one illustration, Figure 1 shows the impressive range of projected carbon dioxide emissions in Morita and Lee's database.

Given such variation among scenarios, they cannot, as a group, define a single detailed route by which the world can avoid the problems foreseen in earlier chapters. Fortunately, however, there are a few generalizations -- two to be precise -- that emerge from the 400-plus scenarios about how to avoid such problems. These are the importance of technological progress to reduce the world's energy intensity (i.e., the amount of energy used to produce a euro's worth of gross world product), and the equal importance of shifting from fossil to non-fossil fuels as our primary energy sources. These generalizations can be used to guide national and international policy making, even before all the analytic loose ends are tied up.

\footnotetext{
${ }^{1}$ United Nations Framework Convention on Climate Change (UN, 1992).
} 


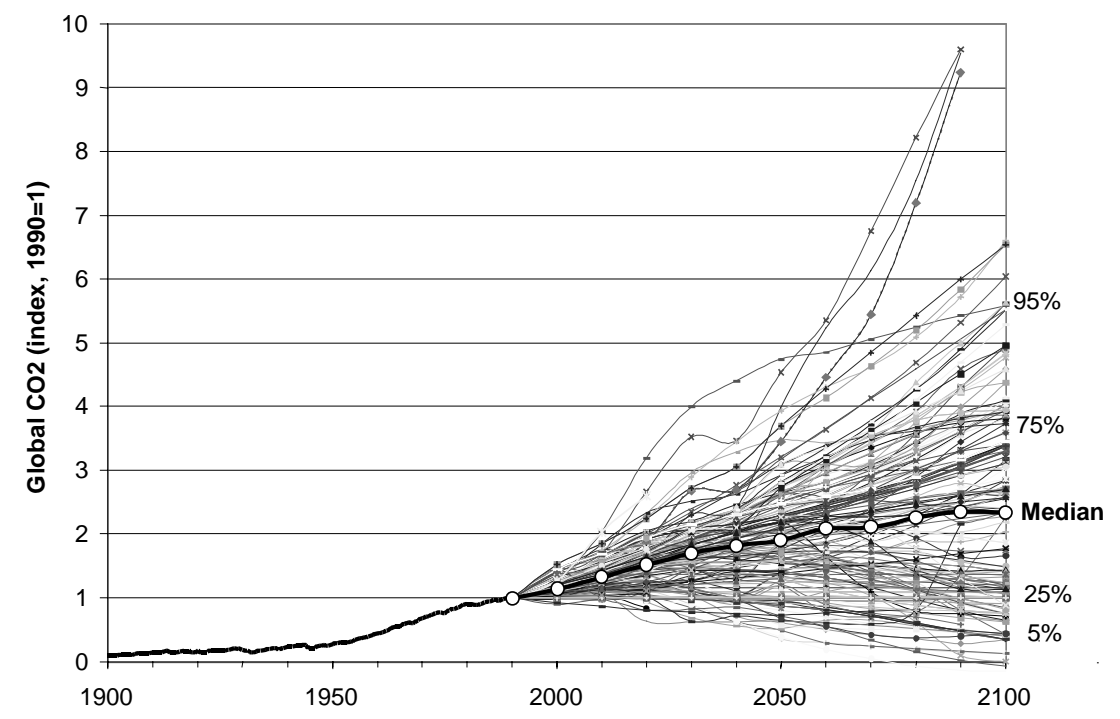

Figure 1: The range of global $\mathrm{CO}_{2}$ emissions, 1900 to 2100, for the scenarios in Morita and Lee's database. Emissions are indexed to a value of one in 1990, when actual energy-related $\mathrm{CO}_{2}$ emissions were about six gigatons of carbon $(\mathrm{GtC})$. Source: Nakićenović et al., 1998b.

This chapter's discussion of how these two lessons are reflected in the scenario literature will address only one well defined subset of Morita and Lee's scenario database, specifically a set of six scenarios developed jointly by the International Institute for Applied Systems Analysis (IIASA) and the World Energy Council (WEC) (Nakićenović et al., 1998a). These six cover the lower $70 \%$ of the distribution in Figure 1, i.e., the $70 \%$ of the database scenarios with the lowest carbon emissions. They have the added advantage of already being extensively documented, having undergone detailed international reviews by ten expert regional groups assembled by WEC.

\section{Six IIASA-WEC Scenarios}

The six IIASA-WEC scenarios are divided into three cases. Case A presents a future of impressive technological improvements and consequent high economic growth. Case B describes a future with less ambitious, though perhaps more realistic, technological improvements, and consequently more intermediate economic growth. Case $\mathrm{C}$ presents a "rich and green" future. It includes both substantial technological progress and unprecedented international cooperation, including major resource transfers from North to South, centered explicitly on environmental protection and international equity. These are driven by explicit policies, including carbon taxes, to reduce global carbon emissions in 2100 to two gigatons of carbon (GtC), one-third the level of global emissions in 1990. Key characteristics of the three cases are given in Table 1. 
Table 1: Summary of the three IIASA-WEC cases in 2050 and 2100 compared with $1990(\mathrm{GWP}=$ gross world product, Gtoe $=$ gigatons oil equivalent, and $\mathrm{GtC}=$ gigatons of carbon). Source: Nakićenović et al., 1998a.

\begin{tabular}{|c|c|c|c|}
\hline & \multicolumn{3}{|c|}{ Case } \\
\hline & $\begin{array}{c}\text { A } \\
\text { High growth }\end{array}$ & $\begin{array}{c}\text { B } \\
\text { Middle course }\end{array}$ & $\begin{array}{c}\mathrm{C} \\
\text { Ecologically driven }\end{array}$ \\
\hline \multicolumn{4}{|l|}{ Population, billion } \\
\hline 1990 & 5.3 & 5.3 & 5.3 \\
\hline 2050 & 10.1 & 10.1 & 10.1 \\
\hline 2100 & 11.7 & 11.7 & 11.7 \\
\hline \multicolumn{4}{|l|}{ GWP, trillion US(1990)\$ } \\
\hline 1990 & 20 & 20 & 20 \\
\hline 2050 & 100 & 75 & 75 \\
\hline 2100 & 300 & 200 & 220 \\
\hline \multicolumn{4}{|l|}{ Global primary energy intensity } \\
\hline 1990 to 2050 & -0.9 & -0.8 & -1.4 \\
\hline 1990 to 2100 & -1.0 & -0.8 & -1.4 \\
\hline \multicolumn{4}{|l|}{ Primary energy demand, Gtoe } \\
\hline 1990 & 9 & 9 & 9 \\
\hline 2050 & 25 & 20 & 14 \\
\hline 2100 & 45 & 35 & 21 \\
\hline \multicolumn{4}{|l|}{ Resource availability } \\
\hline Fossil & High & Medium & Low \\
\hline Non-fossil & High & Medium & High \\
\hline \multicolumn{4}{|l|}{ Technology costs } \\
\hline Fossil & Low & Medium & High \\
\hline Non-fossil & Low & Medium & Low \\
\hline \multicolumn{4}{|l|}{ Technology dynamics } \\
\hline Fossil & High & Medium & Medium \\
\hline Non-fossil & High & Medium & High \\
\hline Environmental taxes & No & No & Yes \\
\hline $\mathrm{CO}_{2}$ emission constraint & No & No & Yes \\
\hline \multicolumn{4}{|l|}{ Net carbon emissions, GtC } \\
\hline 1990 & 6 & 6 & 6 \\
\hline 2050 & $9-15$ & 10 & 5 \\
\hline 2100 & $6-20$ & 11 & 2 \\
\hline Number of scenarios & 3 & 1 & 2 \\
\hline
\end{tabular}

The principal driving forces determining how energy use and supply evolve are population, economic growth, and technology. The top of Table 1 shows that all three IIASAWEC cases use the World Bank's 1992 population projection (Bos et al., 1992). According to this projection, population doubles between 1990 and 2060 to 10.5 billion people, reaches 
11.7 billion in 2100, and eventually stabilizes around 12 billion. Nearly all the population growth occurs in developing countries. The IIASA-WEC study chose not to vary population among the scenarios, arguing it would have led to distracting demographic debates while adding little to the conclusions the study could draw about energy.

Turning to economic growth, in all cases the world gets richer, with the poor getting richer faster that the rich. As shown in Table 1 the gross world product (GWP) in Case A is 15 times higher in 2100 than in 1990. In Case B it is 10 times higher, and in Case C it is 11 times higher, better than in Case B. Case C's greater income in developing regions relative to Case B -- driven by substantial North-to-South resource transfers -- more than offsets Case C's lower income growth in developed, donor regions (due to those same North-to-South transfers). The regional patterns of per capita income growth incorporated in the three different cases are based on extensive historical data relating per capita income growth and economic structure to stages of economic development. The range across the three cases and across regions reflects the range of historical experience.

The third driving force is technology. The basic differences in technology across the three cases are reflected in three of the items in Table 1: resource availability (which depends on technological progress in exploration and extraction), technology costs, and technology dynamics. Technology dynamics refer to the speed with which technological costs come down as we learn and gain experience over time. The technology parameters were also varied within Case A to produce three scenarios, and within Case $\mathrm{C}$ to produce two scenarios, as follows.

In Scenario A1, investments and technological progress focus on oil and gas, and the future availability of oil and gas resources is relatively high. As a result the dominance of oil and gas is perpetuated to the end of the 21 st century. At the other end of the spectrum, Scenario A2 assumes oil and gas resources to be scarce and investments and technological progress to favor coal. The result is a massive return to coal. Finally, in Scenario A3 rapid technological change in nuclear and renewable energy technologies results in a phaseout of fossil fuels for economic reasons rather than due to resource scarcity. Table 2 compares the range of fossil fuel consumption in the scenarios against current estimates of fossil fuel resources.

Table 2: Fossil energy resources and consumption, in gigatons oil equivalent (Gtoe), showing the range in cumulative projected consumption between 1990 and 2050 across the six IIASA-WEC scenarios. Source: Nakićenović et al., 1998a.

\begin{tabular}{|c|c|c|c|c|c|}
\hline & \multicolumn{2}{|c|}{ Cumulative Extraction } & \multirow{2}{*}{$\begin{array}{c}\text { Conventional } \\
\text { Reserves }\end{array}$} & \multirow{2}{*}{$\begin{array}{c}\text { Resource } \\
\text { Base }\end{array}$} & \multirow{2}{*}{$\begin{array}{l}\text { Additional } \\
\text { Occurrences }\end{array}$} \\
\hline & $1850-1990$ & $1990-2050$ & & & \\
\hline Oil & 90 & $180-297$ & 150 & 820 & 1,900 \\
\hline Gas & 41 & $171-253$ & 140 & 870 & $19,100 *$ \\
\hline Coal & 125 & $123-273$ & 600 & 3,400 & 3,000 \\
\hline Total & 256 & $474-823$ & 890 & 5,090 & 24,000 \\
\hline
\end{tabular}

*including methane hydrates

In Case $\mathrm{C}$, which is the most optimistic about technology and geopolitics, nuclear energy is at a crossroads, and two scenarios are included. In Scenario C1 nuclear power proves a transient technology that is eventually phased out entirely by the end of the $21 \mathrm{st}$ 
century. In Scenario C2 a new generation of nuclear reactors is developed that is inherently safe and small scale -- 100 to 300 megawatts electric $\left(\mathrm{MW}_{\mathrm{e}}\right)$ installed capacity -- and finds widespread social acceptability.

\subsection{Energy Use}

Primary energy use grows substantially in the scenarios (Figure 2), but, because of energy intensity improvements, it grows less than GWP. In Case A primary energy use in 2100 is five times what it was in 1990. In Case B it is four times, and in Case C 2.3 times, the 1990 value. However, the global results of Figure 2 hide some important regional differences. While the growth in primary energy use is substantial in developing countries across all scenarios and steady in countries in economic transition, primary energy use in the OECD essentially stabilizes around 2040 in Case B and, in Case C, starts to decline immediately and continues to decrease throughout the 21 st century. In part, this is due to low population growth in the OECD. In part it is due to rapid technological progress and efficiency gains, and in part it is due to Case C's relative shift in economic growth to the South, reflecting the objective of international equity and the mechanism of large North-to-South resource transfers. Thus the expectations of environmentalists who imagine more income in the OECD with less energy use are quite consistent with Case C.

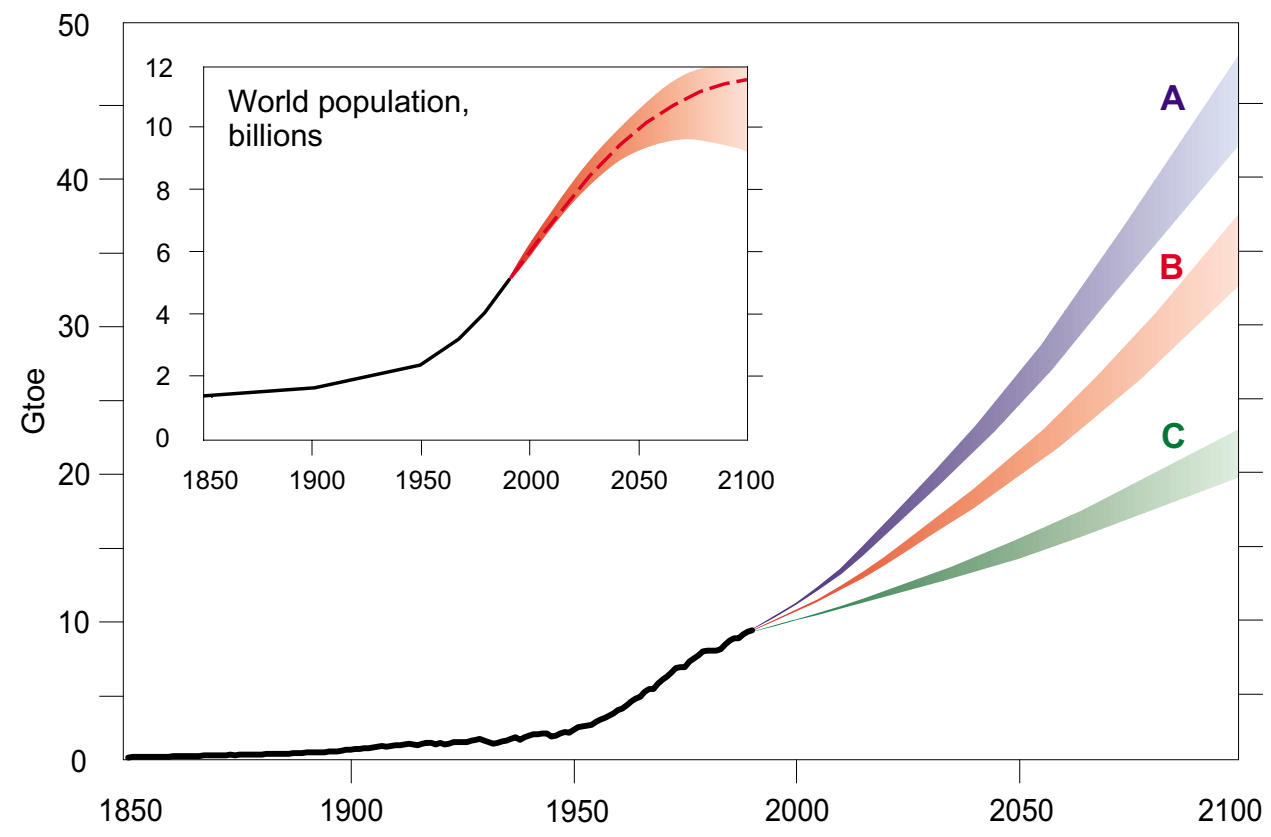

Figure 2: Global primary energy use, historical development from 1850 to 1990 and in the three cases to 2100, in gigatons oil equivalent (Gtoe). The insert shows global population growth, 1850 to 1990 and projections to 2100, in billions of people (source: Bos et al., 1992). Source: Nakićenović et al., 1998a.

As shown in Figure 3 the pattern of final energy use is remarkably consistent across scenarios, with relatively small variations among Cases A, B, and C. Variations among the three Case A scenarios, and the two Case C scenarios, are even smaller. All three cases reflect a continuing pervasive shift toward energy reaching consumers in increasingly flexible, convenient, and clean forms. Ever less energy is used in its original form, such as traditional direct uses of coal and biomass, and ever more energy reaches consumers through elaborate systems of energy conversion and delivery. Simply put, you cannot directly operate 
a personal computer with coal. The overall shift to higher-quality energy carriers and dedicated transport systems, such as pipelines and networks, enhances trade possibilities and promotes similar end-use patterns across regions with fundamentally different primary energy supply structures.

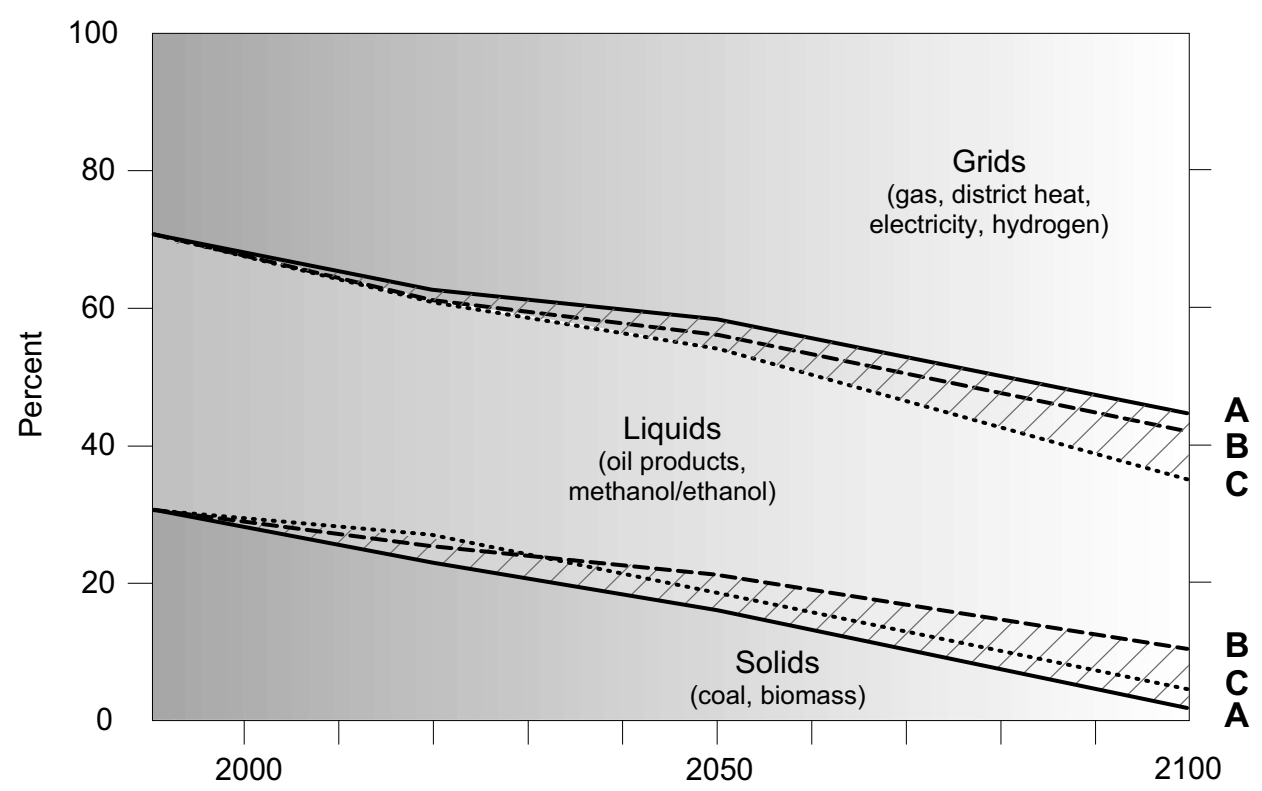

Figure 3: World final energy by form, in percent, as solids, liquids, and grids. Overlapping areas indicate variations across Cases A, B, and C. Source: Nakićenović et al., 1998a.

Turning next to the structure of primary energy supply, the significant result is that there is a wide range of supply structures that can successfully match the persistent final energy trends of Figure 3. The range of primary energy supply structures is shown in Figure 4. Each corner of the triangle corresponds to a hypothetical situation in which all primary energy is supplied by a single category of fuels: oil and gas at the top, coal at the left, and non-fossil sources (renewables and nuclear) at the right. In 1990 their respective shares were $53 \%$ for oil and gas (measured against the horizontal grid lines and the scale on the right), $24 \%$ for coal (measured against the scale on the left), and $23 \%$ for non-fossil energy sources (measured against the bottom scale).

Because of the long lifetimes of power plants, refineries, and other energy investments, there is not enough capital stock turnover in the scenarios prior to 2020 to allow them to diverge significantly. But the seeds of the post-2020 divergence in the structure of energy systems will have been widely sown by then based on research, development, and demonstration (RD\&D) efforts, intervening investments, and technology diffusion strategies. It is these decisions between now and 2020 that will largely determine which of the diverging post-2020 development paths will materialize.

After 2020 all scenarios move away from their current reliance on conventional oil and gas. This transition progresses relatively slowly in Scenario A1 where oil and gas are plentiful. In Scenario A3 and Case C, it progresses more rapidly due to faster technological progress (Scenario A3) or because of energy and environmental policies favoring non-fossil fuels (Case C). In Scenario A2 and Case B, the transition away from oil and gas includes an important contribution from coal, whose long-term market share after 2050 ranges between $20 \%$ and $40 \%$. Nonetheless, little of this coal is used directly. It is instead converted to the 
high-quality energy carriers (electricity, liquids, and gases) demanded by the high-income consumers of the second half of the 21 st century.

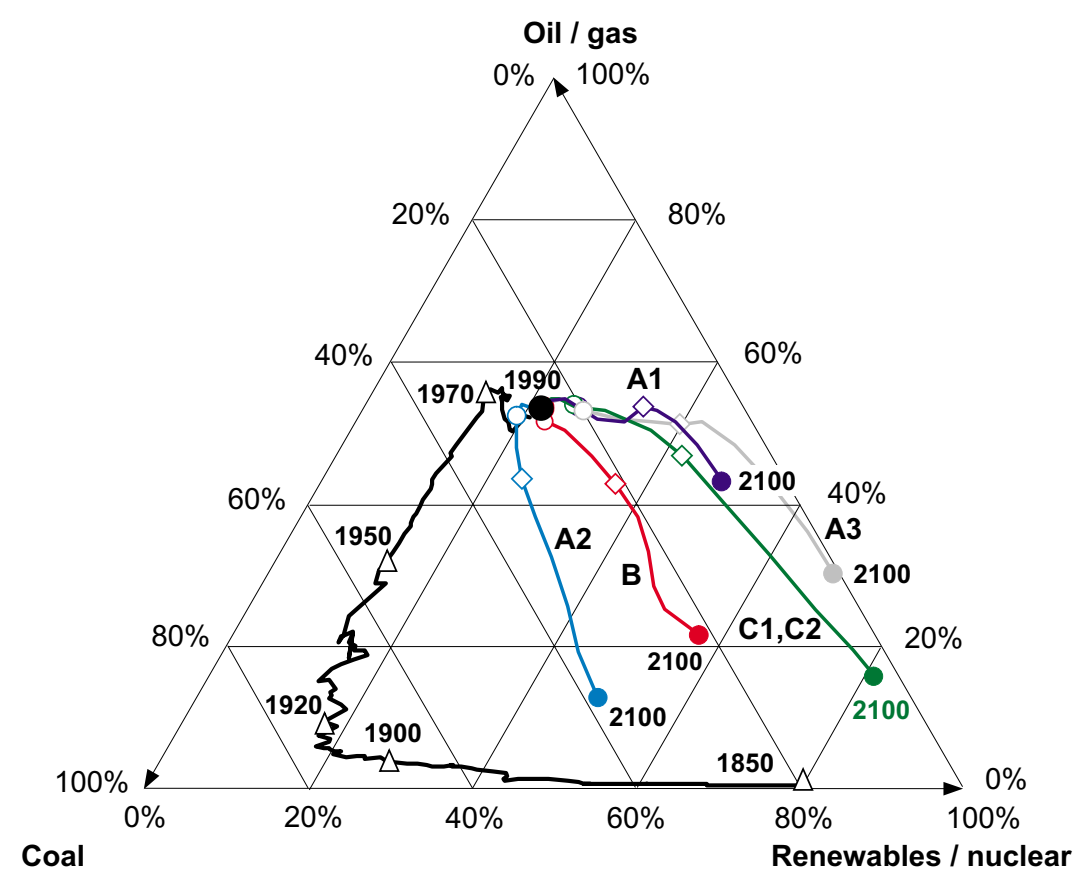

Figure 4: Evolution of primary energy structure, shares of oil and gas, coal, and nonfossil sources, in percent, historical development from 1850 to 1990 (triangles) and in scenarios to 2020 (open circles), 2050 (diamonds), and 2100 (closed circles). For an explanation of the figure see text. Source: Nakićenović et al., 1998a.

\subsection{Carbon Emissions}

Figure 5 divides carbon emissions in the scenarios between the Annex I regions and the non-Annex I regions. The limits in the Kyoto Protocol apply only to Annex I countries and are shown in the aggregate in the figure. Only Case $\mathrm{C}$ is unambiguously in compliance, although Case B and Scenario A3 come close. Scenarios A1 and A2 offer scant hope of compliance.

What brings Case B and Scenario A3 close to compliance is the fact that emissions decrease initially in the newly independent states of the former Soviet Union (FSU) ${ }^{2}$ and Eastern Europe as a result of economic recessions in the early 1990s. As shown in the insert in Figure 5, FSU emissions in 2010 are below their Kyoto limits by about 120 megatons of carbon (MtC) in Scenario A3 and $280 \mathrm{MtC}$ in Case B, a difference sometimes referred to as the "Russian bubble" or "hot air." By itself the Russian bubble does not lead to compliance with the Kyoto Protocol. But with international emission trading the bubble can go a long way in that direction. Case B and Scenario A3 might therefore also comply with the Kyoto limits. Based on estimates of the potential trading price of emission reduction units that cover almost an order of magnitude, from US $\$ 20$ per ton of carbon (tC) up through US\$150 per tC, the total potential value of the Russian bubble is huge, from US $\$ 80$ billion in Scenario A3 to US $\$ 170$ billion in Case B (Victor et al., 1998). Such sums, which would constitute the largest policy-motivated transfer of cash since the Marshall Plan, raise doubts about the practicality

\footnotetext{
${ }^{2}$ Figure 6 shows the regional definitions used in the IIASA-WEC study.
} 
of implementing emission trading. (The mechanics, economics, politics, and possible future of emission trading are discussed in more detail later in the chapter.)

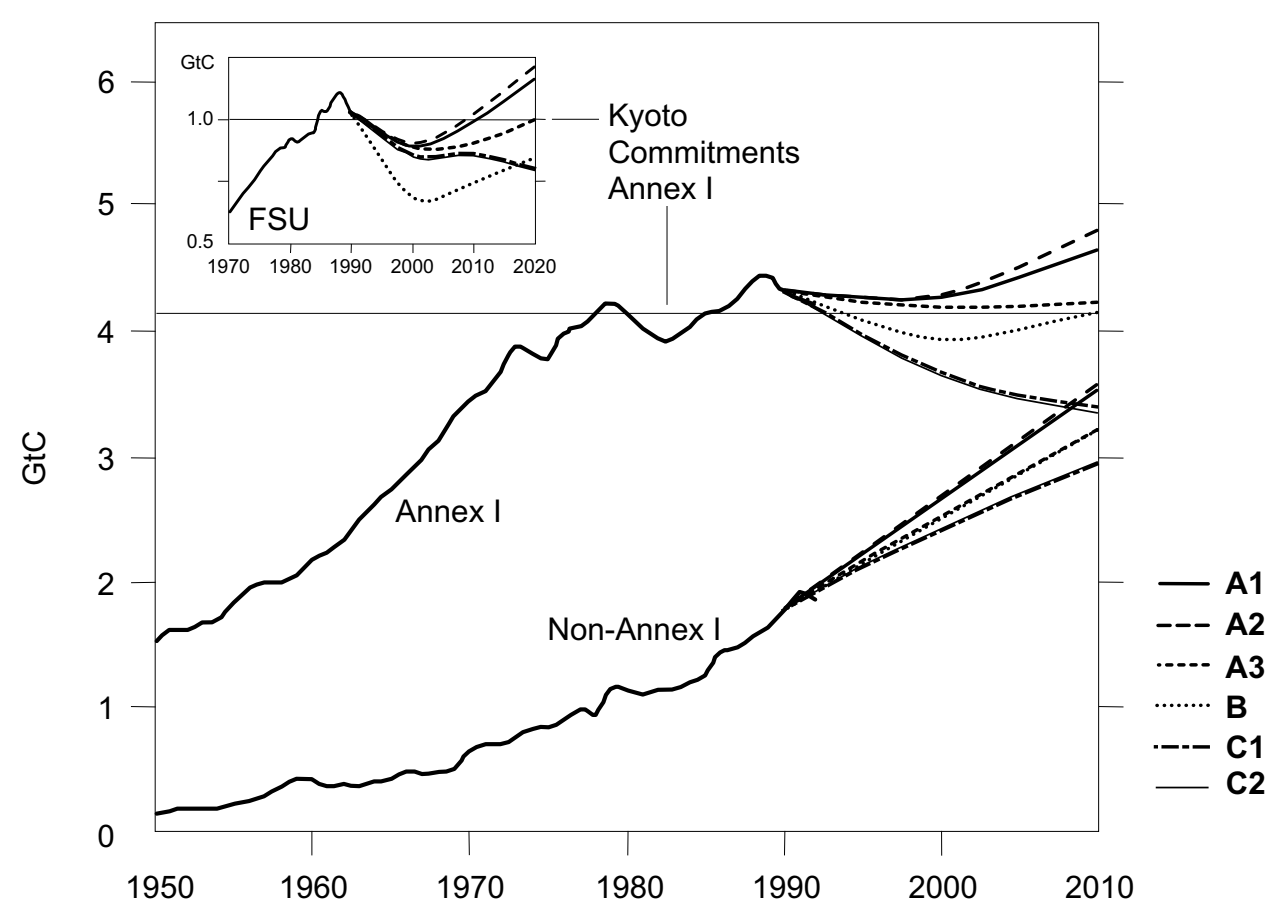

Figure 5: Net energy-related carbon emissions, in $\mathrm{GtC}$, historical development from 1950 to 1992 and in the six scenarios to 2010. Also shown is the agreed aggregate Annex I emission limit of the Kyoto Protocol. The insert shows emissions in FSU compared with 1990. The Russian Federation and Ukraine's 1990 emissions equal their Kyoto limits. Source: Nakićenović et al., 1998a.

Figure 5, however, stops at 2010, which is a very short time horizon for global warming issues. The longer-term picture is shown in Figure 7. For Case B, although emission trading might make it possible to just squeeze under the bar during the Kyoto budget period of 2008-2012, emission levels subsequently take off and never look back. Thus Case B is hardly a long-term answer to potential climate warming. And for the issue of climate warming, it is only the long term that matters. Only Case C and Scenario A3 lead to stabilization of the atmospheric $\mathrm{CO}_{2}$ concentration, consistent with the ultimate objective of the UNFCCC. Case $C$ leads to stabilization below 450 parts per million by volume (ppmv). Scenario A3 leads to stabilization below 550 ppmv assuming that its emissions, which peak around 2060, continue to decline after 2100. 


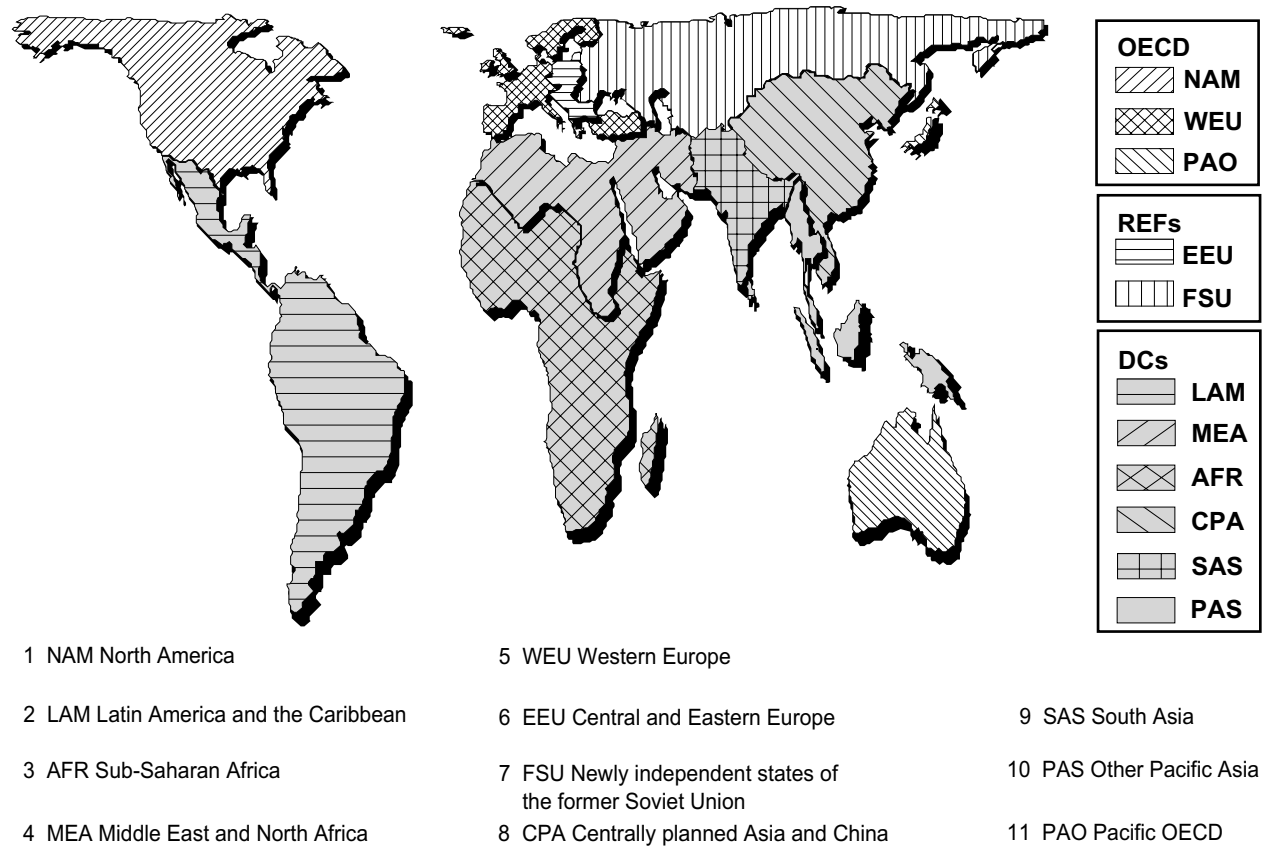

Figure 6: IIASA-WEC study regions. Source: Nakićenović et al., 1998a.

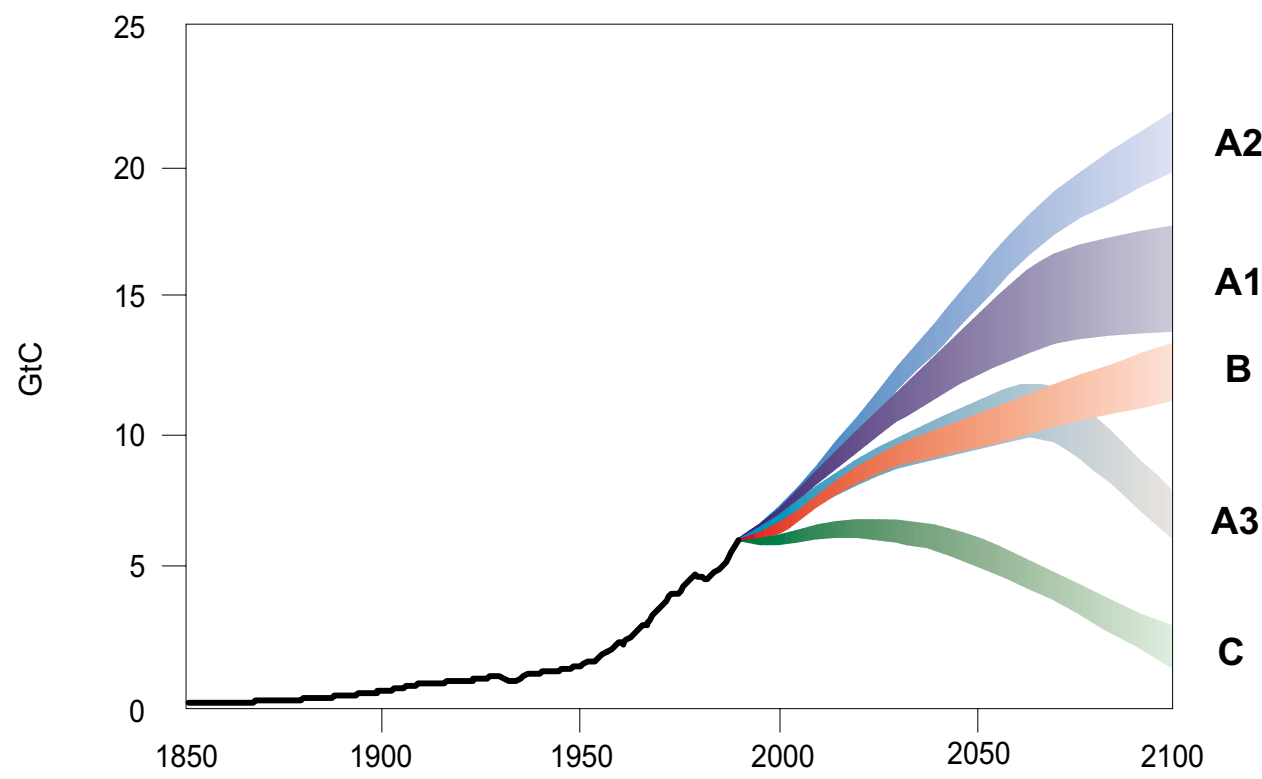

Figure 7: Global carbon emissions from fossil fuel use, 1850 to 1990, and for the six scenarios to 2100, in GtC. For each scenario, the range shows the difference between gross and net emissions. Source: Nakićenović et al., 1998a. 


\subsection{Conclusions}

The four major conclusions of the IIASA-WEC study that are most important for climate change policy are the following.

World energy needs will increase: World population is expected to nearly double over the next century, and economic development must continue, particularly in the South. Most of the population doubling will occur in developing countries where even today two billion people have no access to commercial energy. Providing them with access to convenient and clean energy, providing energy to the almost six billion more people expected by 2100 , and even partially meeting the growth aspirations of the developing world will quite simply require a lot more energy. According to the scenarios, primary energy requirements are 1.5 to 3 times higher in 2050 than in 1990, and 2 to 5 times higher in 2100. Thanks to projected energy intensity improvements, these energy consumption increases lead to even greater increases in economic output -- a 3- to 5-fold increase by 2050 and a 10- to 15-fold increase by 2100 . In all six IIASA-WEC scenarios the gap between rich and poor decreases. However even in the high-growth Case A, per capita income in 2100 in sub-Saharan Africa (AFR), after a century of economic and energy growth, is still only half its 1990 level in the Pacific OECD countries (PAO). The necessity of providing more energy than today and at the same time fewer emissions emphasizes the importance of technological progress and non-fossil fuels.

Resource availability will not be a major global constraint: But while the market for energy will be large and growing, there will be lots of competition from a wide range of potential suppliers. The increased energy demand will not necessarily force the world into the arms of low- or non-carbon renewables and nuclear power. The resource scarcity perceived in the 1970s did not occur as originally assumed, and with technological and economic development, estimates of the ultimately available energy resource base -- including oil, gas, and coal -- will continue to increase. A variety of assumptions about the timing and extent of new discoveries of fossil energy reserves and resources (conventional and unconventional), and about improvements in the economics of their recoverability, are reflected in the scenarios. All, however, indicate that economic development over the next century will not be constrained by geological resources. Nor will geology force the displacement of highcarbon fuels by low- or non-carbon fuels over the next century. Whether we make such a transition will depend on our investment choices. We could choose to invest -- as some people already are -- in coal-based liquid fuels for transportation and in "clean coal" technologies that greatly reduce sulfur emissions and local and regional air pollution. Then the future might look like Scenario A2, with high economic growth and high carbon emissions. Or we could choose to invest in non-fossil technologies -- again as some people are -- and the future might look more like Case C or Scenario A3. It is up to us. Neither geology nor resource economics mandates a particular choice.

There is a continuing pervasive shift toward energy reaching consumers in increasingly flexible, convenient, and clean forms, and this shift in final energy patterns can be met by a wide range of energy supplies: In all scenarios historical trends continue toward electricity and higher-quality fuels, such as natural gas, oil products, methanol, and hydrogen. Solid fuels such as traditional biomass and coal in residential and commercial applications are gradually phased out in all scenarios. Grid-dependent fuels such as electricity, natural gas, and eventually also hydrogen are phased in. But again, the continued shift toward cleaner, more flexible, and more convenient energy forms at the level of end use does not mandate a shift to low- or non-carbon energy sources. In Scenario A2, for example, coal based synthetic 
fuels and electricity make the shift possible even in a high-coal future with high carbon emissions. If we are to have a low-carbon future, we must actively pursue it.

Technological change will be critical, and early investments will make the difference: The difference between the three Case A scenarios is in the rates of technological progress for different energy sources and technologies -- oil, gas, coal, nuclear, and renewables. Technological progress is hardly predictable, and history is full of both surprising failures and surprising successes. Nonetheless, the more RD\&D devoted to a particular technology, the better the odds of lowering its costs and improving its performance. And the quicker we gain experience with a particular technology -- i.e., the quicker it spreads into niche markets and then broader applications -- the faster costs decrease and performance increases. This means that early entrants into the energy market have a significant increasing advantage, other things being equal. As experience with early technological innovations improves their costs and performance, late starting alternatives have increasing difficulty catching up. Future developments are partially locked-in to the direction set by early innovations.

\section{Technological Progress and Non-Fossil Energy Sources}

Of the six IIASA-WEC scenarios, only three are consistent with the UNFCCC goal of climate stabilization. ${ }^{3}$ These are the $\mathrm{C} 1$ and $\mathrm{C} 2$ scenarios, which assume explicit policies to limit carbon emissions, and the A3 Scenario, which does not. What the three stabilization scenarios have in common are, first, significant technological progress particularly in energy end-use and, second, a shift from fossil to non-fossil fuels. In this they well represent the larger collection of scenarios in the literature that aspire to GHG stabilization consistent with the UNFCCC. In the two Case $\mathrm{C}$ scenarios, this shift is largely policy driven by the imposition of carbon taxes. In Scenario A3 the change is driven by economics, as more rapid technological progress in non-fossil technologies makes them increasingly the preferred choice of producers, consumers, and investors. The best indicator of technological progress in Table 1 is the rate at which the global energy intensity improves, i.e., decreases. Historical average improvements in those countries with enough long-term statistics to make the calculation, come out at about $0.9 \%$ per year (Nakićenović, 1987). In the two Case C scenarios, improvements average $1.4 \%$ over the next 100 years, more than $50 \%$ faster than the past long-term average. In Scenario A3, where stabilization comes later and at $550 \mathrm{ppmv}$ instead of $450 \mathrm{ppmv}$, energy intensity improvements essentially maintain the historical trend around $0.9-1 \%$ per year, as they do in Scenarios A1 and A2. What makes the difference among the Case A scenarios is that technological progress in Scenario A3 is focussed on nonfossil fuels.

Energy intensity improvements are nonetheless an imperfect indicator of technological progress because they combine the impacts of technological progress with those of lifestyle changes and of economic structural shifts from highly energy-intensive activities (like steel manufacturing) to ones that are less energy-intensive (like software development). Imagine, for example, two alternatives. In one, the only change is that cars

\footnotetext{
${ }^{3}$ As spelled out in Section 5.1.3, the UNFCCC goal is actually stronger, calling for stabilization "at a level that would prevent dangerous anthropogenic interference with the climate system" (UN, 1992 - Article 2). There is not yet a consensus about what this means in terms of absolute stabilization levels for GHGs and the speed with which they are attained. But stabilization at $450 \mathrm{ppmv}$ before 2100 (Case C) and at 550 ppmv shortly after 2100 (Scenario A3) are within the range being considered.
} 
magically become twice as fuel efficient, cutting fuel consumption per passenger-kilometer in half. In the other, the only change is that twice as many people suddenly begin riding in each car, again cutting fuel consumption per passenger-kilometer in half. The first is exclusively a technological change and the second exclusively a lifestyle change. But their effects on energy intensity should be identical. In practice in the literature the more rapid a scenario's energy intensity improvements, the more likely it is to incorporate greater structural and lifestyle changes as well as more rapid technological progress. The IIASA-WEC study's Scenarios $\mathrm{C} 1$ and $\mathrm{C} 2$, for example, imagine that the trend toward car leasing continues such that car ownership in Western Europe by 2050 is quite low. People rent small highly efficient vehicles for urban commutes and bigger, but still efficient, cars for weekends and longer trips. A large part of longer distance travel is by public transportation, including efficient high-speed rail.

But while it is impossible to separate technological, lifestyle, and structural changes in most scenarios, it is fair to say that probably all scenarios aspiring to climate stabilization incorporate rates of technological progress at least as rapid as those of the last century on average -- and higher in the case of end-use and non-fossil technologies. Certainly that is the overall message from the published literature. If there are scenarios in which radical changes in lifestyles allow success independent of substantial improvements in technology, they are certainly few and hard to find. Indeed well known scenarios that are even more ambitious than the IIASA-WEC study's Scenarios C1 and C2 are especially technology rich. In the New Sustainability Paradigm of Gallopin et al. (1997) "highly efficient energy using equipment become[s] the norm," and, more quantitatively, the menu of possibilities for accomplishing the Factor Four path of von Weizsäcker et al. (1997), in which energy intensity improves at $4 \%$ per year, is heavily dominated by technological improvements. Greenpeace's Fossil Free Energy Future (Lazarus et al., 1993), in which energy intensity improves at $2 \%$ per year for the initial four decades explicitly excludes "substantial lifestyle shifts."

In the above comparison between doubled fuel efficiency in cars and doubled occupancy, technological and lifestyle changes were pure substitutes. More often they are complementary. Technological advances in high-speed rail travel, for example, mean little if they don't attract additional riders to the trains. The interaction between the two will become important later in this chapter when we examine how effective the Kyoto Protocol might be in motivating the technological progress and shifts toward non-fossil energy that the energy scenario literature indicates are necessary to meet the UNFCCC's goal.

\section{The Nature of Technological Progress}

What matters then about the Kyoto Protocol and successive steps in the UNFCCC negotiations is their effectiveness in motivating and accelerating technological progress in energy supply and use, and motivating shifts toward non-fossil energy sources. Before judging the Kyoto Protocol against these standards, it is helpful to review some features of technological progress. The summary in this section depends heavily on Grübler's analysis in his book Technology and Global Change (Grübler, 1998). It concentrates on three points: the difficulty of picking winners and the importance of letting "a thousand flowers bloom;" the high cost and long time required for widespread diffusion; and the phenomenon of technological lock-in. 


\section{1 "Let a Thousand Flowers Bloom"}

Technological progress is highly unpredictable, and failure is much more the norm than success. In the initial stages of a technology's lifecycle, there is usually a rich diversity of contending designs, and picking winners is impossible. Sometimes there will be no winners. Figure 8 shows some of over 1000 patented smoke spark arresters, inventions intended to solve the problem of sparks from wood burning steam locomotives regularly setting American forests ablaze. None of these designs ever enjoyed widespread success as the problem of smoke sparks was solved not by any "add-on" technology in the form of a smoke spark arrester, but by a radical technological change -- the replacement of steam by diesel and electric power -- driven largely by other considerations. Unforeseen developments even in apparently unrelated technologies effectively made a whole patent office worth of smoke spark arrester designs obsolete in short order.

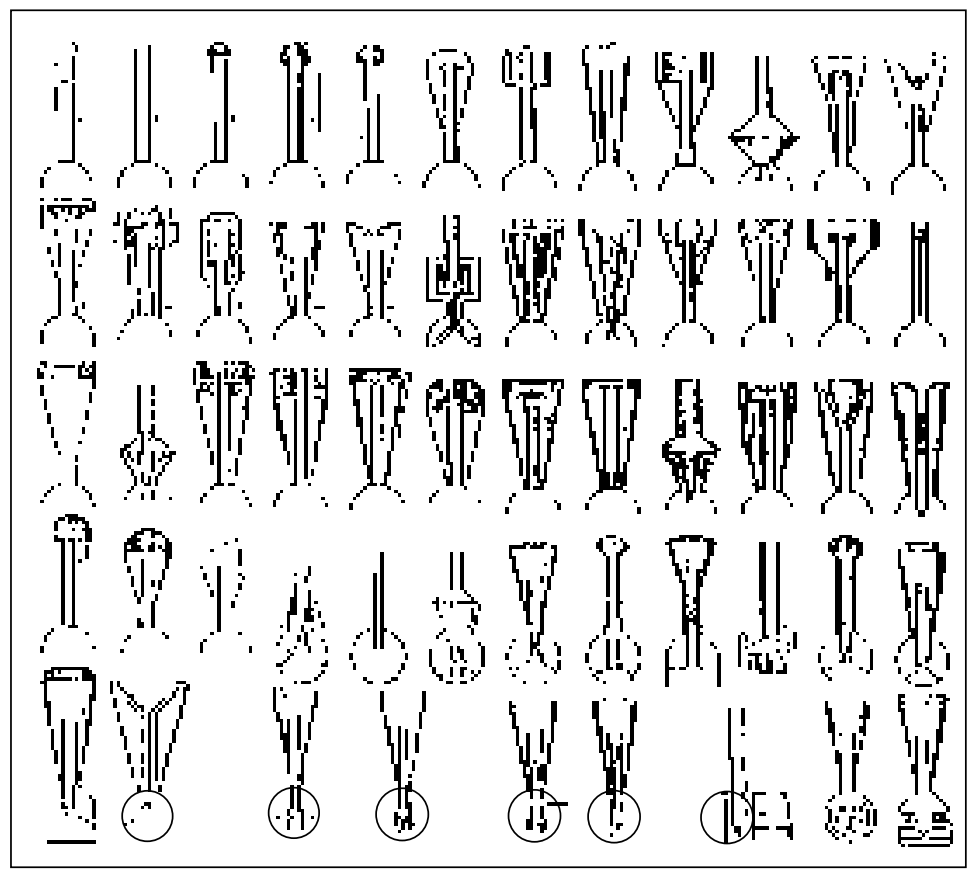

Figure 8: Some of the more than 1000 patented "smoke-spark arresters" for woodburning steam locomotives in the USA. Source: Basalla, 1988.

Even where there is an eventual winner, the initial design will change substantially before it (temporarily) wins the race, and success depends on luck, ingenuity, and perseverance. Consider, for example, the evolution of the bicycle from early designs such as the 1878 Penny-farthing (huge front wheel, tiny back wheel) directed initially at a market niche of "young men of means and nerve." The 20-year evolution to today's safe and comfortable means of transportation that just about anyone can afford and ride depended, in part, on inter-connected developments in related technologies such as Dunlop pneumatic tires and the rear chain drive. It also depended on social developments and changing expectations of both consumers and producers, each responding to the other, that broadened the bicycle's market beyond those "young men of means and nerve." But it would be misleading to think of this as simply a journey from an initial "bad" design to an eventual "good" design. The initial design only got a chance to evolve because it appealed to a niche market through which clever designers and entrepreneurs gained experience that they were able to turn into alternative designs and wider appeal. 


\subsection{Time and Money}

Beyond the engineering, organizational, and entrepreneurial skill and adaptability, the existence of niche markets, and the luck that are all important to technological success, there are also the factors of money and perseverance. Figure 9 shows the costs of photovoltaics in yen per watt installed capacity. Costs fell by almost a factor of 50 between 1973 and 1995, but the investments necessary to accomplish those cost reductions have been large. As shown on the horizontal axis in Figure 9, total expenditures exceed 200 billion yen in 1985 yen, about US $\$ 2.5$ billion. About $20 \%$ of that was spent on R\&D, with the other $80 \%$ going into tangible investments in niche market applications. And a lot more money still has to be invested, even after more than 20 years, before photovoltaics will be competitive enough to diffuse rapidly in mass markets. For energy technologies, with their relatively long lifetimes and slow turnover rates, it can take forty years between a first application and widespread diffusion -- as it has in the case of today's preferred technological option for new electricity generation, gas turbines (Nakićenović et al., 1998a).

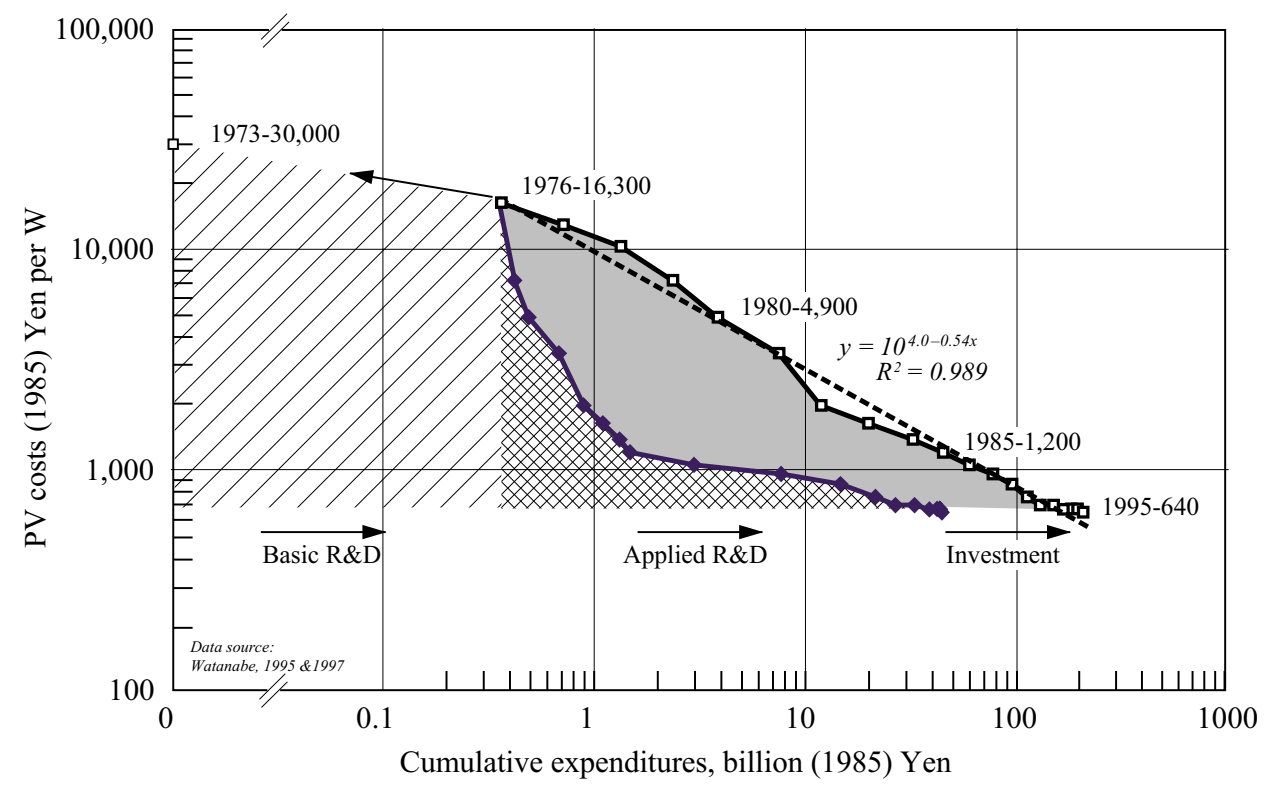

Figure 9: Costs of photovoltaic modules, in yen, per watt installed capacity. Data source: C. Watanabe, Tokyo Institute of Technology and IIASA. Source: IIASA, 1998.

One of the reasons diffusion can be slow is the interconnection between technologies mentioned above. Automobiles, for example, depend on the oil industry to extract, refine, and deliver their fuel. They depend on networks of suppliers for everything from steel and tires to sophisticated electronics. They depend on roads, ferries, tunnels, and bridges. And they depend on economies that include garage mechanics, driving instructors, licensing agencies, traffic control, police, and traffic courts. The mismatch between new technologies (such as natural gas cars) and old networks (such as petrol stations) slows the initial introduction of new technologies, and it likewise slows subsequent technology transfer among regions of the world. Because the free market is not always successful in coordinating the simultaneous transfer of mutually supportive technology networks, this is a prime opportunity for productive government involvement as discussed later in the chapter. 


\subsection{Technological Lock-In}

Finally is the phenomenon of lock-in. As an example, consider the QWERTY keyboard -- the standard keyboard design in which the first six letters on the top row spell QWERTY. This is certainly not the only possible arrangement of keys, and inventors have offered alternatives advertised as ergonomically superior. But the QWERTY keyboard is as pervasive as ever. At least two arguments are given for its success. First, when the QWERTY keyboard was introduced, the mechanical hammers that actually struck the typewriter ribbon and paper were less likely to jam together than was the case with other designs. Second, as its popularity grew, the QWERTY keyboard became transformed into a standard. Typing courses taught typing on QWERTY typewriters, businesses purchased QWERTY typewriters and expected new recruits to be proficient on them, suppliers supplied them, and manufacturers manufactured them. Now, particularly in computer applications, hammer-lock is hardly an issue. But we are firmly locked in to the QWERTY design.

Though less important in the case of the QWERTY keyboard, there are at least two other important contributors to technological lock-in beyond historical early technological advantages (e.g., less hammer-lock) and the advantage of becoming the standard that everyone learns, teaches, uses, and builds. Most important is the phenomenon of technological learning -- as we gain experience producing any given technology, we generally learn to make it better and cheaper. Production costs go down. Performance, quality, and efficiency go up. The result can be technological lock-in. As experience with early technological innovations improves their costs and performance, it widens their advantage over later competitors and makes it increasingly difficult for late-starting alternatives to catch up. The second other important contributor to technological lock-in can be government regulation. If the government requires catalytic converters on every new car, this both kills incentives for designing alternatives and dramatically increases the speed with which experience with catalytic converters is gained, costs are reduced, and performance is increased. Even if government regulations requiring catalytic converters were then replaced with flexible emission limits, the technology would still be the de facto standard, although no longer the de jure standard, and would have intimidating cost and performance advantages over potential competitors with less experience.

\section{The Kyoto Protocol and Incentives for Technological Progress}

These then are the key features of technological progress that must be kept in mind by the negotiators struggling to tie up the Kyoto Protocol's many loose ends. The measure of their labor will be the protocol's (and its successors') eventual success in motivating sufficient technological progress and a sufficient shift from fossil to non-fossil fuels. To do so, implementation of the protocol should encourage "a thousand flowers to bloom" in the field of high-efficiency, low-carbon energy technologies; it should encourage early and persevering investments in such technologies (recognizing that the lion's share of investments must go beyond R\&D to tangible investments in niche markets as in Figure 9); and it should try to exploit technological lock-in in favor of high-efficiency, low-carbon technologies while frustrating tendencies that might lock in higher carbon futures.

How able the Kyoto Protocol is to accomplish all this will depend, in part, on how a number of current debates get resolved. The ones likely to be most important concern, first, the specifics of Kyoto's flexibility mechanisms and, second, how willing the developing 
countries (the non-Annex I countries) will be to take on obligations to limit their GHG emissions.

\subsection{Flexibility Mechanisms}

There are three flexibility mechanisms in the Kyoto Protocol: emission trading, Joint Implementation $(\mathrm{JI})^{4}$, and the Clean Development Mechanism (CDM). Their principal purpose is to reduce the costs of meeting the Kyoto limits or, in economic terminology, to increase efficiency and cost-effectiveness. Flexibility mechanisms make use of the fact that it is more expensive to reduce greenhouse gas emissions in some countries than in others. It costs less, for example, to replace an old inefficient dirty power plant in China or Russia by current technology than it does to squeeze equivalent emission reductions out of the newest state-of-the-art Japanese facility.

This creates the possibility for win-win trades. Russia (or China) should be willing to take on some of Japan's obligations to reduce greenhouse gas emissions at a price that, first, pays Russia (or China) more than it spends on the reductions and, second, costs Japan less than it would spend on the same reductions at home. One side makes money, the other side saves money, and it makes no difference to the environment that greenhouse gas emissions are reduced in Russia or China instead of Japan.

Of the three flexibility mechanisms, emission trading is allowed only among Annex I countries (which would include Russia and Japan in the above example, but not China). Joint Implementation also applies only to Annex I countries, and allows one Annex I country to get credit for reducing its own GHG emissions by investing in a GHG-reducing project located in another Annex I country. CDM, the Clean Development Mechanism, allows an Annex I country to get credit by investing in a GHG-reducing project located in a non-Annex I country. Because JI and CDM are intended to credit emission reductions beyond any reductions that would have happened anyway without the incentives of JI and CDM, these options involve the tricky issue of defining baselines -- i.e., the "reductions that would have happened anyway without the incentives." All three flexibility mechanisms share the difficulty of measuring or calculating emissions and verifying promised reductions. The same would be true for the Kyoto Protocol limits standing on their own, stripped of any flexibility mechanisms.

Detailed rules and guidelines for the three flexibility mechanisms have yet to be worked out, and the Fourth Conference of the Parties (COP-4) in Buenos Aires in 1998 made only limited progress. The current target for having detailed rules and guidelines completed is the Sixth Conference of the Parties (COP-6). COP-6 is currently scheduled for October 2000 in The Hague, although the U.S. would like to postpone it until after the November 2000 U.S. presidential election. Of the differences that need to be resolved, the largest is between the EU and the "Umbrella Group" (a fluid group usually including at least Australia, Japan, and the U.S.) over capping the amount of emission trading an Annex I country can use to bring its emissions beneath its Kyoto limit. The EU prefers a strict interpretation of the "supplementarity" provision in Article 17 of the Kyoto Protocol:

\footnotetext{
${ }^{4}$ The Kyoto Protocol never uses the phrase "Joint Implementation." Nor does it use the phrase "Activities Implemented Jointly" or its acronym, AIJ, which refer to the pilot phase for AIJ established at the First Conference of the Parties (COP-1). In keeping with what appears now to be common practice, this chapter will use JI to refer to the flexibility mechanism described in Article 6 of the Kyoto Protocol.
} 
"The Parties included in Annex B may participate in emissions trading for the purposes of fulfilling their commitments under Article 3. Any such trading shall be supplemental to domestic actions for the purpose of meeting emission limitation reduction commitments under that Article" (UN, 1997).

Specifically, going into the May 31 - June 11, 1999 Tenth Session of the UNFCCC Subsidiary Bodies in Bonn, the EU proposed that "supplemental" be defined as less than half. The Umbrella Group interprets "supplemental" more literally, finding in the word no implication, much less a requirement, that such supplemental reductions be limited in any way. The arguments in the debate cover theoretical, practical, and ethical considerations. The next three sections address each in turn.

\subsubsection{Theoretical Considerations}

The principal theoretical argument against caps is that they reduce economic efficiency. As stated above, trading means that emissions can be reduced wherever reductions cost the least -- at least within the Annex I countries. Since the pattern of reductions resulting from unrestricted trading would, at least in theory, be the absolutely least expensive way to comply with Kyoto's limits, restrictions on trading can only make things more expensive. One rebuttal from those favoring caps is that short-term efficiency (in the sense of minimizing costs) does not lead to the technological progress discussed above as essential to climate stabilization. Under emission trading programs in the United States, for example, utilities can meet emission reduction targets by buying and junking old highly polluting automobiles. This is cheaper than developing new technologies, and therefore more efficient, but it does little to promote technological progress. Similarly, if Russia and Ukraine are allowed to sell all their hot air to countries such as the U.S. and Japan, the short-term results may be compliance with the Kyoto limits and savings for all parties to the trade, but lower incentives in the U.S. and Japan for technological progress. In the long-run, argue the critics of unrestricted trading, those reduced incentives will mean slower technological progress, less likelihood of meeting the UNFCCC climate stabilization goal, and higher ultimate costs. They may also lead to what Hourcade and Le Pesant (1999) call "dynamic inconsistency" in which slow initial technological progress due to cheap trading makes future stricter emission limits prohibitively expensive to countries like the U.S. Such countries could fail to develop the technologies needed to meet, at a cost they consider acceptable, the stricter limits that might be required several decades hence. Indeed most economically optimal GHG reduction paths push the bulk of the reductions to the second half of the 21 st century when, among other things, technological progress is assumed to have made them cheaper (e.g., Wigley et al., 1996). Hourcade and Le Pesant fear that in the face of excessive costs because of their technological lag, countries such as the U.S. would drop out of the UNFCCC process or otherwise cause global efforts to abate potential climate change to unravel.

Which side of the theoretical argument you prefer depends on how perfect you imagine the future emission trading market will be. There are good reasons to expect that it

\footnotetext{
${ }^{5}$ The Kyoto Protocol refers sometimes to Annex I of the UNFCCC and sometimes to Annex B of the Kyoto Protocol. Essentially the parties listed in Annex I of the UNFCCC are required to meet the limits listed in Annex B of the Kyoto Protocol. There are two Annex I countries not included in Annex B, Belarus and Turkey. As Annex I countries they can presumably participate in emission trading and JI, although they have no Kyoto Protocol commitments of their own. This chapter uses the phrase "Annex I countries" to refer interchangeably to the countries of Annex I or Annex B. Such usage is not precise, but it is less confusing and wordy than the alternative.
} 
will be "sufficiently perfect." Because emission permits can be shipped electronically, delivery costs are effectively zero. Moreover, a number of institutions have already entered the competition to become either the central trading exchange or leaders in brokering and auditing emission reductions (e.g., Times of London, 1999; Inter Press Service, 1999; Sydney Morning Herald, 1999), and the experience they are accumulating should steadily decrease transaction costs associated with finding accurate market information and trading partners.

Market proponents also argue that unrestricted trading shifts the incentives for emission-reducing technological progress to those who can make such progress most costeffectively. Here the arguments based on economic theory may get too impractical even for those inclined toward free market solutions. It may be true that assuming well-defined, smooth regional production functions for $R \& D$ within an equally well-defined macroeconomic model shows that unrestricted emission trading in a perfect market causes R\&D investments to migrate to where they generate the greatest assumed return, e.g., FSU and developing countries (Buonanno et al., 1999). But it is neither terribly surprising, nor pragmatically convincing, as the assumption of perfect markets and well-defined R\&D production functions in these countries is something of a stretch. For the skeptics in this case, several anecdotes may be more persuasive in making the case that unrestricted trading may be at least as good an incentive for technological progress as trading caps.

"Niagara Mohawk Power Corporation (NMPC) completed a unique trade with Arizona Public Service (APS) in which APS transferred 20,000 sulfur dioxide $\left(\mathrm{SO}_{2}\right)$ allowances to NMPC, and in return, APS received 2.5 million tons of $\mathrm{CO}_{2}$ reductions from NMPC. The $\mathrm{CO}_{2}$ emission reductions made by NMPC are below 1990 levels and have been recognized by the Department of Energy as applying toward APS's voluntary greenhouse gas reduction commitment. As a consequence of the transfer, the two companies pursued other environmental health benefits. First, instead of releasing the $\mathrm{SO}_{2}$ into the atmosphere, NMPC donated the $20,000 \mathrm{SO}_{2}$ allowances to three non-profit environmental organizations to be permanently taken off the market. Second, the tax benefit associated with the donation, expected to be about $\$ 650,000$, will be reinvested in projects which will further reduce $\mathrm{CO}_{2}$, including a $\mathrm{CO}_{2}$ reduction project in Mexico. This trade illustrates how quickly businesses internalize the concepts of emissions trading and identify market opportunities that would never be realized under strict command-and-control regulation...

"International Fuel Cells [IFC] views emissions trading as a means to catalyze an innovative financing strategy to increases their sales. [IFC], a subsidiary of United Technologies, designs, manufactures, and sells commercial fuel cell power plants that produce electricity and cogenerated heat. Their product produces virtually zero air pollutants and, because of its high efficiency, helps reduce greenhouse gas emissions. IFC seeks to pool the emissions reductions achieved by each of its customers, broker trades, and use the proceeds to discount the price of the fuel cells to those customers. This example reveals the potential of emissions reductions markets to stimulate the financing of investments in newer and cleaner technologies such as fuel cells" (Knopman and Susman, 1998).

There is a second theoretical argument for capping emission trading -- it will lead to absolutely lower carbon emissions during the Kyoto budget period, 2008-2012. Caps will 
force some Annex I countries to make domestic reductions they would otherwise cover by buying hot air, but the reductions in Russia and elsewhere that constitute that hot air will be unchanged. The net result will be greater absolute reductions than with unrestricted emission trading. There are two rebuttals that critics of caps might offer. First, the same additional reductions would be accomplished more efficiently if they were included in the limits set in Kyoto and then met using a system with unrestricted trading. Second, the additional carbon reduction between 2008 and 2012 is likely to be heavily outweighed by the additional reductions made possible in the long run through uncapped emission trading that assures that each euro devoted to carbon reduction will be spent in the most efficient way.

\subsubsection{Practical Considerations}

Second are the practical considerations surrounding trading caps. There are those in Europe who consider that too many powerful Americans are already beyond ever being persuaded to see the merits of capping emission trading. Noting that U.S. ratification is essential for the Kyoto Protocol to enter into force, ${ }^{6}$ they argue it is necessary, and therefore in this case desirable, to trade away the trading cap in exchange for U.S. participation. Bohm (1999) also argues that lowering the costs of meeting the Kyoto limits (by allowing unrestricted trading) makes it easier for Annex I countries to accept more stringent future limits than they might otherwise. He also notes that unrestricted trading, by raising the prospective revenues of emission permit sellers, increases the incentives for non-Annex I countries to join the protocol.

The biggest practical argument in favor of caps may be that they would limit a potentially huge and unrestricted windfall that might otherwise prove counterproductive to Russia and Ukraine. With sufficient transparency and accountability, permit revenues could reinforce economic progress and responsible institutions in those countries, but without sufficient transparency and accountability, large windfall revenues could undercut progress. To the extent they undermine current incentives for reform and discipline, they risk becoming partly counterproductive.

\subsubsection{Ethical Considerations}

The ethical objection of Europeans to unrestricted emission trading is that it allows some countries (read the U.S.) to effectively buy their way out of reducing their carbon emissions, and that's not fair! The argument is that those countries that have created the problem through their high carbon emissions during the last century have a responsibility to clean themselves up first. This is recognized in Articles 3 and 4 of the UNFCCC (quoted below), which commit the developed countries to taking the lead in reducing GHG emissions. For the U.S. to meet its Kyoto limit by buying up large quantities of unused "emission reduction units" from countries in severe economic recessions is seen as something distinctly less than the leadership required by the UNFCCC.

\footnotetext{
${ }^{6}$ Formally, the Kyoto Protocol will enter into force 90 days after 55 countries have ratified it, including enough to account for $55 \%$ of Annex I CO 2 emissions in 1990. The U.S. accounted for $36 \%$ of Annex I CO $\mathrm{CO}_{2}$ emissions in 1990, with Western Europe and the former Soviet bloc each accounting for 25\%. It is theoretically possible for the protocol to enter into force without the U.S., but politically unlikely. As of August 27, 1999, the protocol had been ratified by 14 countries, mostly small island states and none a significant GHG emitter.
} 
The issue of fairness in the UNFCCC process is extremely important, affecting not just the debate about whether to cap emission trading, but also nearly all other aspects of implementing the Kyoto Protocol and negotiating subsequent steps. For that reason, this section goes beyond fairness in emission trading to address the rather unusual role that the UNFCCC text assigns to fairness considerations, how such considerations appear in the Kyoto Protocol, and how such considerations might play out in subsequent negotiations.

The general nature of international negotiations (some would argue of all negotiations) is that no country is compelled to agree to a proposal that, all things considered, it does not consider to be to its advantage. If the proposal on the table does not offer you a net gain compared to your current situation, then don't sign. Negotiations are in essence about joint gains. Each and every party to an agreement should be better off after the agreement, judged by their own standards and taking all factors into account, or they should not take part in the agreement. Notice that fairness does not enter into this description. Although negotiators will appeal to various principles of fairness in any negotiation (more on this later), international negotiators to not generally come together to make the world a more fair place. They come together to strike deals that will make each of their countries better off. They came together to negotiate the UNFCCC to protect their countries -- which involves protecting other countries as well -- from all the potential impacts of climate change. Such protection is something that most agree can be better done cooperatively than unilaterally. That is what motivated the UNFCCC.

The UNFCCC, however, and the process of implementing its objectives through negotiating specific binding protocols, contain a few features that give additional importance to issues of fairness. In short, the convention frames the problem as one of collectively deciding on a safe level at which to stabilize atmospheric GHG concentrations, and then working out a fair division of the burdens required to meet that safe level. The convention text gives some guidelines about what should be considered safe and what should be considered fair, but, as is evident from the following excerpts, it leaves many more questions up in the air.

\section{"Article 2: Objective}

The ultimate objective... is to achieve... stabilization of greenhouse gas concentrations in the atmosphere at a level that would prevent dangerous anthropogenic interference with the climate system. Such a level should be achieved within a time frame sufficient to allow ecosystems to adapt naturally to climate change, to ensure that food production is not threatened and to enable economic development to proceed in a sustainable manner...

\section{"Article 3.1}

The Parties should protect the climate system for the benefit of present and future generations of humankind, on the basis of equity and in accordance with their common but differentiated responsibilities and respective capabilities. Accordingly, the developed country Parties should take the lead in combating climate change and the adverse effects thereof...

\section{"Article 4.2(a)}

Each of these Parties [Annex I Parties] shall adopt national policies and take corresponding measures... [that] will demonstrate that developed countries are taking the lead in modifying longer-term trends 
in anthropogenic emissions consistent with the objective of the Convention... and taking into account the differences in these Parties' starting points and approaches, economic structures and resource bases, the need to maintain strong and sustainable economic growth, available technologies and other individual circumstances, as well as the need for equitable and appropriate contributions by each of these Parties to the global effort regarding that objective..." (UN, 1992).

This framing of the problem -- collectively determining a safe stabilization level and then a fair division of the costs -- creates a number of difficulties. First, there is no objective answer to the question of how safe is safe enough, even if all scientific uncertainties could be eliminated. It is itself a subject for negotiation as individuals -- and countries -- will answer it differently. Partly this is a matter of different tastes and aversions to risk -- in the words of the revisionist "Don't do unto others as you would have them do unto you. They may have different tastes." Partly it is a function of how the costs of increasing safety, and the benefits that result, fall differently on different parties. This means that the first part of the task set by the UNFCCC is inextricably tied to the second, agreeing on a fair division of burdens.

The difficulty in agreeing to a fair division of burdens is that there is no fair division principle that is both theoretically and practically perfect. Quite a few fair division principles exist, from the very simple ("split the difference" or "first come, first served") to the more complex and philosophical. Many have been analyzed in terms of their implications for burden sharing under the UNFCCC and other environmental agreements (Young, 1994; Rose et al., 1998; Torvanger and Godal, 1999). Young (1994) organizes contending fair division principles into three categories: parity (sharing a burden equally among all parties), proportionality (sharing the burden in proportion to, for example, the parties' abilities to pay, or their current emission levels, or their populations), and priority (allocating the burden principally to one party, as in the polluter-pays principle). Rarely do negotiators proceed by first agreeing on a particular fair division principle, then applying it to their problem and completing the deal. Much more realistic is the case where various fair division principles serve as focal points around which the negotiators coordinate their expectations. If the seller of a used car, for example, states his asking price, and the buyer responds with a lower offer, both will immediately calculate the midpoint of the two offers. They may not move to the midpoint immediately or even eventually, but the fairness principle of "splitting the difference" (parity) makes the midpoint a significant (if unspoken) reference point. If two business partners are negotiating about how to divide future profits, a division proportional to their investments will almost certainly be an important reference point, spoken or unspoken. In the UNFCCC negotiations we see appeals to fairness principles within all three categories. Parity of emission rights in the form of an identical per capita emission entitlement for each individual has been advocated by some developing countries. Proportionality principles of several sorts are combined in the Kyoto Protocol. First, limits are defined in terms of percentage reductions from actual emissions in 1990, making reductions in part proportional to 1990 levels. Then overlaid on this proportional allocation is another based on how burdensome reductions in different countries were judged to be. Thus Iceland's limit is $10 \%$ higher than its 1990 emissions, and the EU's is 8\% below 1990. Priority is reflected in the requirement that the developed countries take the lead in reducing emissions.

None of this is to say that the Kyoto Protocol represents an elegant blending, explicitly crafted by the parties, of simpler fairness principles. The argument is that fairness principles that appeal in one way or another to parity, proportionality, or priority become 
focal points around which negotiators frame their arguments and proposals. Each is emphasizing principles that serve her interests -- the G-77 may argue for national reductions proportional to cumulative per capita emissions since the start of the Industrial Revolution, and the OECD may argue for reductions proportional only to current annual emissions (or better yet a prior year with higher OECD emissions). And each is using what political power he has to nudge (or shove) the outcome further in his favor. But the exercise of power and the pursuit of self-interest are not unrestrained. However contentious the negotiation process and messy the eventual compromise, both are guided by appeals to parity, proportionality, and priority.

To this first proposition -- that no single fairness principle is both theoretically and practically perfect, and that alternative fairness principles serve as focal points around which negotiators can coordinate expectations -- let me add a second. That is that successful negotiations often happen in stages. They start with straightforward applications of uncomplicated fairness principles. These tend to be relatively blunt instruments that leave many joint gains on the table. As negotiators learn more about each other's interests and abilities (and perhaps come to trust each other more), they manage to overlay additional fairness principles on top of the original agreement that capture and share these joint gains and make all parties better off. Consider the Convention on Long-Range Transboundary Air Pollution (LRTAP), adopted in Geneva in November 1979. The first quantitative pollution reduction agreement under LRTAP came in 1985 when a number of European countries plus Canada (a group that became known as the 30\% Club) agreed to reduce national sulfur emissions or transboundary fluxes by at least 30\%, in 1993 relative to 1980 (UN, 1985). This is straightforward proportionality. Everyone's reduction is proportional to her status quo emissions in 1980. It was also economically inefficient. Squeezing additional reductions out of more modern Western European facilities was generally more expensive than eliminating the same amount of pollution through improving many aging facilities in Eastern Europe. But a more complicated -- and efficient -- protocol was politically out of reach. By 1994, however, after almost a decade of joint analysis and cooperative experience, essentially the same countries were able to negotiate the Second Sulfur Protocol (UN/ECE, 1994). In this, percentage reduction requirements (in 2000 relative to 1980) range from $0 \%$ for Portugal and Greece to $83 \%$ for Germany, and very few countries have identical requirements. But the benefit is a net gain for everyone, taking into account both their environmental and financial interests. The price of these joint gains is the added complexity of making reduction requirements partially proportional to their impact on ecosystems -- rather than just the 1980 status quo emissions.

The immediate application of these propositions to the ethics of capping emission trading is that advocates of unrestricted trading can argue that no overriding fairness principle exists to which their critics can now appeal to trump the compromise worked out in Kyoto. The Kyoto Protocol was an exercise in negotiating joint gains. It was certainly shaped -although not determined -- by focal points implied by a variety of fairness principles. But it was a package agreed to by the U.S. and other negotiators because each calculated the agreement, as a package, to be in its own self-interest. Assuming unrestricted emission trading, the U.S. judged itself better off with the agreement than without when all the benefits, costs, and political implications were taken into account. To restrict trading now would be, in the eyes of the U.S., to increase its costs after the fact. That the U.S. argues, appealing to another fairness principle, is simply not fair.

The prospective sellers of emission reduction units are on the same side of the above argument as the prospective buyers. The EU's proposed trading caps would erect trade 
barriers restricting exports from the likely producers of emission reduction units, like Russia and Ukraine, even before the new commodity is fully created. In reality it is unlikely that Russia and Ukraine's calculations concerning the Kyoto Protocol turned as finely on estimates of their new exports as the U.S.'s did on estimates of its new imports. They have certainly not been as vocal as the U.S. in resisting the EU's proposals.

Section 6 on "Next Steps" will return to the role that might be played by fairness issues. But one final possible rebuttal to ethical criticisms of unrestricted emission trading should be cited to complete the discussion. It is the economic argument that the unborn generations, particularly in the developing world, who are to be the principal beneficiaries of the Kyoto Protocol will also benefit critically from economic development in the meantime. Inefficient global carbon reductions can only slow that development relative to efficient global carbon reductions. If the most ethical approach is that which most benefits those unborn generations whose climate is being molded by our emissions, then unrestricted trading should be preferred. It delivers the same emission reductions as does restricted trading, but is less of a drag on economic development. Richels et al. (1996) offer a quantitative version of essentially the same argument in calculating that, because of trade effects, the economic slowdown in the OECD caused by emission limits with no trading would spill over and incur costs in non-OECD countries -- even when they have no limitations on their own emissions. Indeed it can be argued that true equity would require not just unrestricted trading, but also including developing countries as legitimate sellers. In this case, the developing countries would receive tremendous trading revenues (Nordhaus and Boyer, 1999) and boost their development prospects even more.

\subsection{Participation of Developing Countries}

The second critical debate concerns "meaningful participation" by developing countries. In the 1997 Byrd-Hagel resolution, the U.S. Senate effectively promised, by a 95-0 vote, not to ratify the Kyoto Protocol unless it "mandates new specific scheduled commitments to limit or reduce greenhouse gas emissions for Developing Country Parties within the same compliance period [as for Annex I parties]" (Congressional Record, 1997). The Clinton administration has reframed the issue somewhat, by promising to secure "meaningful contributions" from the developing countries before submitting the protocol for Senate ratification. But the developing countries take the position that they will only participate if there is first an acceptable agreement on equity considerations. As stated by Shukla (1999), "The aim of climate negotiations is to minimize the welfare losses and not the emissions or mitigation costs alone. Minimizing the welfare losses requires dealing up front with equity -- that is, the distribution of [the] total welfare burden, including the distribution of side payments. This is the basic aspect of [the] developing country perspective in climate negotiations... The substantial issue in global negotiations, then, is not efficiency but distribution or equity." In a "non-paper" at the 1998 SBSTA $^{7}$ meeting in Bonn, the G-77 took the position, that "Until the question of emission rights and entitlements has been addressed equitably, it will not be possible to have emission trading." This ties their concern about equity directly to the negotiation issue closest to America's heart.

Equity principles that appeal to developing countries include those that would allocate GHG emission entitlements in proportion to population or assure net welfare gains inversely proportional to a country's gross domestic product (GDP) (Shukla, 1999; Rose et al., 1998;

\footnotetext{
${ }^{7}$ Subsidiary Body for Scientific and Technological Advice.
} 
Torvanger and Godal, 1999). The implications of the first are relatively easy to calculate, although operational proposals along these lines usually envision a requirement that per capita GHG emissions converge over time on a common value by a common date. The convergence value, date, and differentiated paths for developed and developing countries would be consistent with climate stabilization at a safe level, but otherwise open to negotiation. For the second principle even the calculations are much harder. Given the hundreds of billions of dollars in international transfers that would be at stake, the prospect of an agreed consensus projection, nation-by-nation, of the future net welfare impacts of uncertain mitigation costs, and even more uncertain mitigation benefits, is remote to say the least. But whether based on equal per capita emission entitlements or net welfare gains inversely proportional to GDP, these options all involve huge transfers from developed to developing countries as a matter of right -- as indeed the developing countries argue that any equitable arrangement should.

The previous section argued that negotiators seldom start by working out a consensus on an overall definition of fairness to guide their efforts. Nor is it important that the final product conform to some shared overriding fairness principle (although each party will invoke useful, and often different, fairness principles when selling an agreement to their constituency at home). Victor (1999) is more blunt, "Conventional wisdom holds that fair agreements are more effective... conventional wisdom is largely incorrect." Insistence by developing countries on reaching an overriding agreement on equity first would thus seem to create two very large hurdles for the Kyoto Protocol and its prospective successors. First, it puts agreement on an overriding definition of equity front and center, contrary to historical practice in successful international negotiations big and small. Second, the definitions of equity proposed by the developing countries are extremely expensive for the North -- many would say prohibitively expensive. Estimates of what it would cost the OECD to buy emission permits in the event of per capita entitlements and a $20 \%$ reduction in global emissions by 2010 relative to 1990 (admittedly a much tighter criterion than the Kyoto Protocol), run over US $\$ 100$ billion per year (Rose et al., 1998). This is much higher than the Russian bubble's prospective cost, cited above, of US $\$ 100$ billion over the whole Kyoto budget period.

The hurdle created by the Byrd-Hagel resolution in the U.S. seems equally high. Victor (1999) argues that the variable that best explains differential contributions to international environmental agreements is willingness to pay. He also notes that wealthy countries are usually more willing to pay for environmental protection. ${ }^{8}$ Consistent with this observation, developing countries have demonstrated a very low willingness to pay for potential climate change abatement in view of more immediate environmental problems with air, water, and land pollution, not to mention pressing non-environmental issues of health, education, and economic growth. Nor are developing countries likely to start behaving like rich environmentalists any time soon.

The task then is to find a path forward from Kyoto that promises to motivate the technological progress found necessary in the scenario literature, while dodging both the Scylla of the trans-Atlantic emission trading spat and the Charybdis of the standoff between the South insisting on equity first and the U.S. Senate holding the Kyoto Protocol hostage to developing country commitments starting in 2008. In addition, success may depend on

\footnotetext{
${ }^{8}$ This leads to an empirical correlation between contributions and wealth that has led some analysts to discern fairness principles at work when, Victor contends, they should really see only variations in willingness to pay.
} 
making politically palatable the huge transfers of cash to Russia and Ukraine implied by unrestricted emission trading.

The final sections of this chapter attempt to offer one possible "rosy scenario" that a country pondering this task might want to choose. The intent is to pursue the lessons extracted from the chapter's opening review of the scenario literature -- that technological progress, particularly in low- and non-fossil technologies, is the key to success. But this rosy scenario must also take into account the political constraints discussed above, and their theoretical and practical impact on technological progress. Section 6 starts by considering a strategy based on the two IIASA-WEC Case C scenarios that clearly comply with the Kyoto Protocol, moves on to the one other IIASA-WEC scenario that promises long-term climate stabilization (Scenario A3), and then focuses on how a country might make parallel progress at home and in UNFCCC negotiations to see the Kyoto Protocol's flexibility mechanisms put to politically acceptable productive use.

\section{Next Steps}

The IIASA-WEC study describes its two Case C scenarios as "rich and green." Of the six scenarios, these are the ones most in line with the green agenda. Carbon emissions drop most steeply, the income gap between North and South narrows the most, and, in the C1 Scenario, nuclear power disappears. The South develops faster than in the muddling-through Case B, and the OECD manages a steadily improving standard of living with a steadily declining consumption of energy. In the words of the study there is "unprecedented international cooperation centered explicitly on environmental protection and international equity." Measured solely on projected GHG emissions, a Case C strategy (with or without nuclear power) matches best the goal of the UNFCCC. Of the IIASA-WEC study's six scenarios, only $\mathrm{C} 1$ and $\mathrm{C} 2$ promise clear compliance with the Kyoto Protocol and $\mathrm{CO}_{2}$ stabilization as low as $450 \mathrm{ppmv}$.

But in deciding whether to choose a Case $\mathrm{C}$ strategy, one must also weigh the likelihood of success. Here Case $\mathrm{C}$ presents difficulties. It envisions transfers from the OECD to developing countries climbing from about $0.5 \%$ of the OECD's GDP in 2000 to approximately $5 \%$ by 2100 . Those are big numbers, especially compared to the present (unmet) UN guideline of $0.7 \%$ for official development aid (ODA). The money transferred to the South would come from sweeping carbon and energy taxes or their regulatory equivalents. Political agreement on energy and carbon taxes is still proving elusive for even the relatively green EU. For America's taxophobic Congress, which in 1995 provided ODA equal to only $0.12 \%$ of U.S. GDP (down from $0.20 \%$ in 1991), it will be even more difficult to negotiate major new taxes solely to produce revenues to be sent abroad. The U.S. Congress is still withholding US\$1.7 billion in dues owed to the UN, the Senate passed the Byrd-Hagel resolution 95-0, and many members of Congress would see an increase in ODA as pouring good money into a black hole.

The large North-to-South transfers incorporated in Case $\mathrm{C}$ depress OECD economic growth below even its modest level in the muddling-through Case B. The arguments for undertaking this sacrifice are faster economic development in the South and a reduced danger of climate change. However, faster development in the South is uncertain and politically remote, and the serious impacts of climate change are still decades away even in the most pessimistic scenarios. In a world of 2- to 6-year election cycles in the public sector and of 
ever shortening holding periods and day traders in the world's stock exchanges, the near-term prospects for such arguments proving persuasive would seem slim to none.

Case $\mathrm{C}$ is also not necessarily terribly appealing to the South. Although for the developing regions, per capita income grows in Case $\mathrm{C}$ faster than in Case $\mathrm{B}$, it is still behind the pace of Case A. To the (very large) extent that developing regions place economic growth ahead of the long-term risk of global warming, they are likely to find the incentive offered by the North in Case $\mathrm{C}$ insufficient to turn them away from higher growth ambitions as exemplified by Case A. Indeed several of the expert teams from developing regions that WEC assembled to review preliminary study results considered even the study's Case A growth rates too low for their regions. Case $\mathrm{C}$ is thus a difficult strategy to sell in the South as well as the North.

This may be the reason for Case C's final difficulty -- it is already almost 10 years behind schedule. In the IIASA-WEC study, Case C policies were assumed to start in 1990. Obviously they did not. The delay does not undercut the basic arguments for Case C. In the short term, a delayed Case $\mathrm{C}$ could still meet the schedule of the Kyoto Protocol. In Figure 5, even if the Case $\mathrm{C}$ trajectories are moved 10 years to the right and adjusted for Annex I emission changes since 1990, they still will meet the Kyoto limits (although emission trading may become more important than it would have been). In the long term, even delaying implementation of Case $\mathrm{C}$ for another 10 years to 2010 would only add $20 \mathrm{GtC}$ to Case C's cumulative (1990 to 2100) emissions of $540 \mathrm{GtC}$. This would still result in the $\mathrm{CO}_{2}$ concentration stabilizing below 450 ppmv. But while the substantive arguments for Case $\mathrm{C}$ hold despite the 10-year delay, the lack of progress towards Case $\mathrm{C}$ policies in the eight years since the 1992 Earth Summit in Rio de Janeiro argues against Case C as a realistic option. Remember also that in addition to being a political optimist at this stage, an advocate of a Case $\mathrm{C}$ strategy must also be a technological optimist -- it incorporates energy intensity improvements averaging 1.4\% per year, less ambitious than Greenpeace (Lazarus et al., 1993) and Factor Four (von Weizsäcker et al., 1997) but still over 50\% more ambitious than the long-term historical average.

An alternative to a Case C strategy is the example of Scenario A3. In Scenario A3 the energy supply shifts away from fossil fuels because of economics, not resource constraints, and the best argument for Scenario A3 is perhaps the increasing belief in business circles that carbon reduction is a smart business objective. Business has always pursued increased efficiency (although they have not always striven to motivate their customers to do the same), but their interest in "carbon efficiency" is new. The Pew Center on Global Climate Change, for example, was created in 1998, and its 21-member Business Environmental Leadership Council includes such established names as ABB, Boeing, BP Amoco, DuPont, Enron, Shell, Toyota, and PG\&E Corporation. The first two principles of the Council's Joint Statement read:

" 1 . We accept the views of most scientists that enough is known about the science and environmental impacts of climate change for us to take actions to address its consequences.

"2. Businesses can and should take concrete steps now in the U.S. and abroad to assess opportunities for emission reductions, establish and meet emission reduction objectives, and invest in new, more efficient products, practices and technologies."

BP Amoco has adopted a goal of reducing the company's GHG emissions by $10 \%$ from 1990 to 2010 and has already implemented an internal emission trading system in order 
to reach that goal most efficiently. Note that a $10 \%$ reduction is more aggressive than any national limit agreed to in the Kyoto Protocol (although several countries have internal goals that are more ambitious than their formal Kyoto commitments). Even more aggressive are Shell's objective of a 10\% reduction between 1990 and 2002 and DuPont's goal of a 65\% reduction between 1990 and 2010 .

Ten years ago few would have predicted such behavior. Economists would argue that no rational firm should invest money to reduce carbon emissions as long as carbon emissions are free. Doing so would put the firm at a disadvantage relative to competitors not wasting money on reducing outputs that could be disposed of freely in unlimited quantities. Only if governments act to internalize the costs of carbon emissions by instituting taxes, requiring emission permits, or mandating emission limits or control technologies should a rational firm react. That was the logic then. Rather than conclude now that companies like BP Amoco, Shell, and DuPont are irrational, the more popular explanation of investments in carbon reduction is that these companies are indeed very rational, and are rationally hedging against, or even betting on, the possibility that governments will internalize carbon emission costs. Many Annex I countries now have policies and goals with carbon reduction targets, most of them have voluntary programs to encourage reductions or have increased RD\&D targeted on reducing carbon emissions, and a few have actually imposed carbon or energy taxes. They have signed the Kyoto Protocol, and a prudent businessman should therefore anticipate that the costs of carbon emissions will (or at least might) be internalized and prepare accordingly. This interpretation is reinforced by the efforts of active businesses to assure that they get credit against future carbon reduction mandates for their anticipatory earlier reductions. It is also reinforced by the emission trading that is already taking place (see examples above and in the references) as firms, seeking an advantage in the carbon-constrained economy that they anticipate, move to snap up the cheapest carbon reduction opportunities early.

Indeed the private sector appears to be out ahead of the public sector, particularly in the field of emission trading. While negotiators in Buenos Aires, Bonn, and elsewhere struggle to agree before 2001 on the details of particularly the Kyoto flexibility mechanisms (but also other troublesome items such as GHG sinks), the companies listed above, and others, have already gained initial experience in finding emission trading partners, finding auditors and brokers, finding mechanisms to register trades and establish legitimacy, and completing trades. As the number of such trades grows so do the incentives and the expertise of ancillary businesses -- auditors, brokers, and exchanges. Together, they make a growing lobby with an increasingly vested interest in seeing emission limits implemented and full emission trading accepted. They will have invested significantly to gain an advantage in a carbon-constrained business environment, and to make those investments pay off, they will likely also spend political capital to assure that governments indeed create exactly that carbon-constrained business environment. ${ }^{9}$ Such a lobby may be particularly important in persuading a key player, the U.S., to ratify the Kyoto Protocol and remain engaged in the process of developing the next steps to be taken in implementing the overall UNFCCC. Right now, the argument against the Kyoto Protocol in the U.S. is largely that it will disadvantage the U.S. economy and hurt U.S. competitiveness due to increased costs. A business lobby arguing that carbon constraints, properly implemented, would be an important competitive advantage would be a significant counter-argument.

\footnotetext{
${ }^{9}$ Experience with the Montreal Protocol to reduce ozone depleting substances may be a good precedent. Victor (1999) notes that "even the U.S., UN debtor par excellence," has fully paid its contribution to the protocol's voluntary Multilateral Fund. He comments, "If America did not pay, environmental groups, as well as firms that have in invested in ozone-benign technologies, would crucify the government."
} 
For a country seeking to marry a Scenario A3 strategy to the UNFCCC process and the Kyoto Protocol, it would seem sensible to encourage and facilitate the initiatives of companies seeking an early advantage in a carbon-constrained business environment. First, encouraging such initiatives motivates exactly the sort of investments in low- and non-carbon technological progress that are required in all scenarios that accomplish climate stabilization. And the earlier these investments are made the more potential they have for partially locking future progress in to a low-carbon development path. This lock-in potential has a technological and economic dimension -- more early experience will likely translate into quicker cost and performance improvements and ever-wider applications. It also has a social or political dimension -- as the networks of suppliers, customers, repairers, installers, financiers, trainers, brokers, auditors, other intermediaries, and lobbyists grow, so does their appetite for more business with the technologies they know best. Thus reinforcement of business initiatives representing early movement in a Scenario A3 direction would seem eminently desirable from a long-term perspective. Reinforcement should include at the very least mechanisms by which early reductions can be reassuringly certified (as the Niagara Mohawk - Arizona Public Service reductions were by the U.S. DOE's voluntary reductions program) even if such certification cannot be formally recognized by the UNFCCC before the international negotiations are complete. ${ }^{10}$ Or it could go further to institute domestic tradable permit programs both to build experience and to send price signals to "strengthen the incentive for technological innovation that is essential for future emission reductions" (Kopp et al., 1999).

Reinforcement of such initiatives also has at least two short-term advantages. It cultivates a business lobby that may be essential to assuring especially U.S. ratification of the Kyoto Protocol, and it makes immediate progress towards implementing the sort of emission trading needed to bring at least the IIASA-WEC Scenario A3 into compliance with the Kyoto Protocol. Failure on either of these fronts -- U.S. ratification of the Kyoto Protocol or actual compliance in 2008-2012 with Kyoto's limits -- would be a serious blow to international cooperation to stabilize the climate.

But a successful marriage of a Scenario A3 strategy and the Kyoto Protocol will require more than reinforcing early private initiatives. It will also require the expansion of Joint Implementation (JI) projects among Annex I countries and aggressive initiation of Clean Development Mechanism (CDM) projects in developing countries. The short-term arguments for JI and CDM are that the former may be an essential step in making emission trading politically palatable in general, while the latter may be essential for U.S. ratification. The reasons JI may be politically essential for emission trading are the magnitude of the prospective revenues for Russia and Ukraine, and the generally poor record in both countries of putting to good use smaller transfers in the past. The very features of JI that make it economically inefficient -- lots of transaction costs associated with defining baselines, cost accounting, monitoring, and verification -- make it a promising vehicle for introducing the sort of tighter controls and transparency that will be necessary for OECD countries to consider transferring to Russia and Ukraine the kind of money estimated above. Assuming that the OECD will insist on attaching strings to emission trading revenues of Russia and Ukraine if full trading is to go forward, JI is an important opportunity for designing, testing, and improving such strings. CDM has similar advantages, but, of more immediate importance, it is the mechanism that most realistically promises to engage the developing

\footnotetext{
${ }^{10}$ For a thorough discussion of the monitoring, verification, certification, reporting, and accounting issues associated with emission trading, plus alternative designs for domestic systems and past experience, see Tietenberg et al., 1998.
} 
countries, and thus may be a route to a sufficient level of "meaningful participation" of developing countries for the U.S. to declare itself satisfied.

These are the short-term reasons that progress on JI and CDM is important. Their longer-term importance is their contribution to technology transfer. Although the IIASAWEC scenarios do not assume that every future improvement in the cost or performance of low- and non-carbon technologies is immediately diffused throughout the world, Scenario A3 is a high-growth market oriented scenario. Technological diffusion follows economic incentives mediated by functioning markets. And the diffusion of low- and non-carbon technologies around the world is essential for the eventual climate stabilization reached in Scenario A3. In reality, or course, those markets function imperfectly. Energy markets in most countries are skewed by uneven subsidies, charges, and regulations and by pricing and payment practices that can garble price signals. Even relatively smoothly functioning markets are poor at transferring simultaneously to distant locations a new technology along with its supporting networks of installers, repairers, spare parts suppliers, fuel suppliers, trainers, financiers, and others. JI and CDM can be used to overcome some, although hardly all, of these difficulties and facilitate the type of technology diffusion necessary for a Scenario A3 strategy. To the extent possible, progress on JI and CDM should reinforce private interests in gaining credit for inexpensive international carbon reductions. Firms should be, and already are, interested in the most inexpensive reductions for which they can get credit, and the advantages of expanding corporate JI and CDM initiatives are the same as the advantages of encouraging their early initiatives in carbon reductions and emission trading. It increases political support and helps lock us in, both socially and technologically, toward a lower carbon future.

The G-77 and China have taken the position that the technology transfer called for in the UNFCCC should not take place only through the market. That is not at odds with the proposal here. To suggest that businesses be encouraged to aggressively expand CDM projects in order to reap efficient emission reduction credits does not exclude expanding additional technology transfer through the UN's Global Environment Facility (GEF). A party to the UNFCCC can certainly advocate making progress on both technology transfer fronts at once. The idea is to mobilize private money through CDM projects as well as the principally public money mobilized through the GEF.

Private business involvement in buying "certified emission reductions" (the phrase the Kyoto Protocol reserves for CDM emission reductions) should also help shift the current perspective on developing country reductions in a more promising direction. The immediate reality is that, although the South is much more likely than the North to suffer from climate change, southern interests dictate the investment of their available funds in development rather than in climate change abatement. Whether this is explained by higher discount rates, different priorities, higher or lower moral perspectives, or whatever, does not really matter. The point is that the South, left to its own devices, is highly unlikely to invest in abating climate change. If any investment is going to be made, it will have to come from the North. The most persuasive reason that private firms or northern taxpayers could have for investing in climate change abatement in the South is that the South offers the most cost-effective abatement opportunities. Yes, there are many people, particularly in the South, who argue for northern investment in southern climate change abatement for moral and ethical reasons (Shukla, 1999; Torvanger and Godal, 1999). But cost-effectiveness has a much wider appeal. However, northern investments in southern climate change abatement are cost-effective only if they are not too risky, that is, if the South can deliver effective abatement with a high enough reliability. It is thus in the interests of both North and South to assure that the South 
has a good product to sell -- reliable, predictable, cost-effective mitigation. CDM projects with extensive participation by private firms who are obliged by their shareholders to give top priority to the bottom line could reinforce this perspective on climate change abatement. Seeing inexpensive climate change abatement as a new southern product to be developed and marketed to northern firms and governments, may be less ethically satisfying to the South than seeing the UNFCCC negotiations as a quest for justice. But it may be more lucrative and better for southern development. A developing country pursuing such a strategy would focus on improving quality (i.e., reliability), expanding production (i.e., opportunities for CDM projects), and cutting transaction costs (i.e., cutting red tape and improving information). Eventually, such a country may judge the less restricted option of emission trading as sufficiently more lucrative than CDM to justify joining Annex I. It would presumably then accept a modest mutually agreed limit on its own future GHG emissions in order to have a free hand in the emission trading market. A like minded developed country would be aggressively assisting its firms in finding partners, assuring quality, and lowering transaction costs.

In the case of the Russian bubble, JI was presented above as an opportunity to introduce confidence-building controls and transparency to energy investments and transfers to Russia and Ukraine -- as a chance to design, test, and improve the sort of strings that the OECD will likely want to attach to emission trading with Russia and Ukraine. But for fullscale trading, OECD politicians will probably demand full-scale strings -- or ropes. Scaling up the yet-to-be-established strings of JI and CDM to a strength commensurate with the scale of the envisioned emission trading revenues (the range cited above was US $\$ 20$ billion to US $\$ 170$ billion) will require more creativity than can be offered in this chapter. One suggestion of the IIASA-WEC study, however, is worth repeating. It starts with the recognition that FSU is situated between two major energy-consuming regions. To its West, growth is slowing in Western Europe (WEU), but consumption will stabilize at high levels and gas imports will rise. To the East are the fastest-growing markets of the future. By 2000, or shortly thereafter, annual energy demand in the developing countries of Asia will reach three gigatons oil equivalent (Gtoe), surpassing that of WEU, Eastern Europe (EEU), and FSU combined. It would be very much in FSU's interest, but also very expensive, to build a network linking its oil and particularly its gas resources, both in central Asia and Siberia, to the large markets to its East and West. If rules on emission trading to be adopted at COP-6 were to include a mechanism through which Russia and Ukraine could be required to invest their revenues in such a network, three things might happen. First, it could accelerate Eurasian progress on natural gas, the cleanest of the fossil fuels and a good transition fuel toward non-fossil synthetics. This would help to partially lock in FSU and maybe a good part of Asia to a cleaner long-term development path. Second it could leverage a short-term Russian and Ukrainian windfall into a possible long-term revenue stream from energy sales. And third it could make the prospect of a US $\$ 100$ billion transfer to Russia and Ukraine more politically palatable.

\section{Summary}

The important lessons from the scenario literature in general, and from the IIASAWEC scenarios in particular, are the importance of technological progress to reduce the world's energy intensity and the importance of shifting from fossil to non-fossil fuels as our primary energy sources. Three (half) of the six IIASA-WEC scenarios manage to match the UNFCCC's objective of stabilizing the atmospheric GHG concentration by combining 
sufficient technological progress with a large enough shift toward non-fossil fuels. Of these, Scenarios $\mathrm{C} 1$ and $\mathrm{C} 2$, which achieve the lowest GHG emissions and concentrations, assume carbon taxes and large North-to-South transfers that appear politically unrealistic in the nearterm. More promising is Scenario A3 in which the energy supply shifts away from fossil fuels because of economics driven not by carbon taxes but by cost-reducing investments.

A strategy based on Scenario A3 and taking into account the constraints of the current UNFCCC negotiations should consider including the following.

- Support for unrestricted emission trading under the Kyoto Protocol. First, Scenario A3's carbon emissions as shown in Figure 5 and Figure 7 will require at least full emission trading, and maybe a bit more (CDM perhaps?) to be brought into compliance with the Kyoto commitments. Failure to comply with Kyoto's limits would undercut the prospects of any strategy. Second, against the standard of successfully motivating technological progress, the arguments reviewed above in favor of unrestricted emission trading appear stronger than the arguments in favor of trading caps. In particular, unrestricted emission trading appears more likely to encourage "a thousand flowers to bloom," to provide early encouragement for the large essential tangible investments in niche markets needed to supplement R\&D, and to motivate early technological, business, and political developments that will tilt technological lock-in toward a low-carbon future.

- Support for JI and CDM. JI and CDM provide mechanisms, first, to aid technology transfer; second, to gain experience on a manageable scale with strings that might eventually make large emission trading revenues for Russia and Ukraine politically palatable; third, to engage developing countries to an extent the U.S. might judge sufficiently "meaningful" to justify ratification; and, fourth, to encourage a southern perspective on low-cost mitigation opportunities as commodities to be profitably marketed rather than hostages to justice.

- Post-Kyoto agreements that combine northern willingness to pay with inexpensive southern mitigation. Carbon emissions are growing fastest in developing countries and must eventually be brought under control if the UNFCCC's GHG stabilization objective is to be realized. But the willingness to pay that exists to avoid climate change lies in the developed countries. Neither the ambitions of the Byrd-Hagel resolution (developing countries commit as early as 2008 to emission reductions) nor the ambitions of those seeking large, lucrative, early entitlements for the South are likely to be realized. More plausible is a scenario where good initial experience with northern investments in southern mitigation opportunities leads to further investments. This would tie North-toSouth transfers to the emission reductions that the North is willing to pay for. It would be consistent with fairness principles expecting the North to bear all initial mitigation costs for a long time, it would allow northern firms to choose the investments that profit them most, and it would take advantage of markets to motivate needed technological progress and improve efficiency.

- Post-Kyoto agreements that encourage but do not demand too ambitious energy intensity improvement rates. Figure 7 shows Scenario A3's $\mathrm{CO}_{2}$ emissions increasing after 2010 with global reductions only occurring in the second half of the 21 st century. This reflects economic recovery in FSU and EEU and the time required for new technologies to improve and diffuse widely (in a scenario with an aggregate energy intensity improvement just slightly better than long-term historical experience, i.e., $1 \%$ per year). Future protocols should consistently seek to accelerate energy intensity improvements, but should not make success dependent on substantial, unprecedented changes in the 
long-term aggregate energy intensity improvement rate. This may require post-Kyoto limits that allow emissions to rise initially before beginning their decline.

- Domestic initiatives reinforcing private incentives to invest in increasing energy efficiency and shifting away from fossil fuels. These might include programs to reinforce private participation in emission trading, JI, and CDM by recognizing early carbon reductions, emission trades, and JI and CDM investments, by reducing transaction costs, or by instituting directly a domestic trading program.

- Supportive government investments in $R D \& D$ and infrastructure. Money may not always be able to quickly buy technological progress, but it can certainly make it easier. Governments could usefully increase their RD\&D funding targeted on improving efficiency and the production and use of non-fossil energy. (As a fraction of GDP, federal energy R\&D in the U.S., for example, is now at its lowest point in 30 years; PCAST, 1997.) Governments also have important roles to play in the early expansion of infrastructures needed if new technologies are to become widespread. Public funds, for example, built most of the roads that have helped addict us to the internal combustion engine. They have a role in building the new infrastructures to help wean us from such addictions -- whether through expanding alternative fuel networks, creating markets for intermittent renewable electricity, or facilitating carbon emission trading.

\section{References}

Basalla, G. (1988), The Evolution of Technology, Cambridge University Press, Cambridge, UK.

Bohm, P. (1999), "International Greenhouse Gas Emission Trading - with Special Reference to the Kyoto Protocol," Department of Economics, Stockholm University, forthcoming in C. Carraro (editor), Efficiency and Equity of Climate Change Policy, Kluwer Academic Publishers, Dordrecht, Netherlands.

Bos, E., M.T. Vu, A. Leven, and R.A. Bulatao (1992), World Population Projections 19921993, Johns Hopkins University Press, Baltimore, MD, USA.

Buonanno, Paolo, Carlo Carraro, Efrem Castelnuovo, and Marzio Galeotti (1999), "Efficiency and Equity of Emission Trading with Endogenous Environmental Technical Change," forthcoming in C. Carraro (editor), Efficiency and Equity of Climate Change Policy, Kluwer Academic Publishers, Dordrecht, Netherlands.

Congressional Record (1997), Congressional Record, Vol. 143, pp. S8138-S8139, Washington, DC.

Gallopin, G., A. Hammond, P. Raskin, and R. Swart (1997), Branch Points, Stockholm Environment Institute, PoleStar Series Report 7, Boston, MA, USA.

Grübler, Arnulf (1998), Technology and Global Change, Cambridge University Press, Cambridge, UK. 
Hourcade, Jean-Charles, and Thierry Le Pesant (1999), "Negotiating Targets, Negotiating Flex-Mex: The Economic Background of the US-EU Controversy," forthcoming in C. Carraro (editor), Efficiency and Equity of Climate Change Policy, Kluwer Academic Publishers, Dordrecht, Netherlands.

Inter Press Service (1999), “World Bank Setting Up Prototype Carbon Fund,” July 28, 1999.

IIASA (1998), "From Bikes to Bytes: The Past and Future of Technology and the Environment," Options, Winter, 1998, International Institute for Applied Systems Analysis, Laxenburg, Austria.

Knopman, Debra S., and Megan Susman (1998), "Trading Air Emissions for Environmental and Economic Benefit: Success Stories from the Private Sector," Progressive Policy Institute, Washington, DC, February 1998, (http://www.dlcppi.org/texts/commerce/emission.htm).

Kopp, Raymond, Richard Morgenstern, William Pizer, and Michael Toman (1999), “A Proposal for Credible Early Action in U.S. Climate Policy," Weathervane, Resources for the Future, Washington, DC, (http://www.weathervane.rff.org/features/feature060.html).

Lazarus, Michael, Lisa Greber, Jeff Hall, Carlton Bartels, Steve Bernow, Evan Hansen, Paul Raskin, and David von Hippel (1993), "Towards a Fossil Free Energy Future: The Next Energy Transition," Stockholm Environment Institute - Boston Center, Boston, MA, USA.

Morita, T., and H.-C. Lee (1998), IPCC SRES Database, Version 0.1, Emission Scenario Database prepared for IPCC Special Report on Emission Scenarios, (http://wwwcger.nies.go.jp/cger-e/db/ipcc.html).

Nakićenović, Nebojša (1987), "Technological Substitution and Long Waves in the USA," The Long-Wave Debate, Tibor Vasko (editor), Springer-Verlag, Berlin.

Nakićenović, Nebojša, Arnulf Grübler, and Alan McDonald, editors (1998a), Global Energy Perspectives, Cambridge University Press, Cambridge, UK, New York, NY, USA, ISBN 0-521-64569-7, (http://www.iiasa.ac.at/cgi-bin/ecs/book_dyn/bookcnt.py).

Nakićenović, Nebojša, Nadejda Victor, and Tsuneyuki Morita (1998b), "Emissions Scenarios Database and Review of Scenarios," Mitigation and Adaptation Strategies for Global Change, Vol. 3, Nos. 2-4, 95-120.

Nordhaus, William D., and Joseph G. Boyer (1999), "Requiem for Kyoto: An Economic Analysis of the Kyoto Protocol," Yale University, New Haven, CT, USA, (http://www.econ.yale.edu/ nordhaus/homepage/dicemodels.htm).

PCAST (1997), Federal Energy Research and Development for the Challenges of the Twenty-First Century, The President's Committee of Advisors on Science and Technology, Washington, DC.

Richels, Richard, Jae Edmonds, Howard Gruenspecht, and Tom Wigley (1996), "The Berlin Mandate: The Design of Cost-Effective Mitigation Strategies," Climate Change: Integrating Science, Economics, and Policy, N. Nakićenović, W.D. Nordhaus, R. Richels, and F.L. Toth (editors), CP-96-1, International Institute for Applied Systems Analysis, Laxenburg, Austria. 
Rose, Adam, Brandt Stevens, Jae Edmonds, and Marshall Wise (1998), "International Equity and Differentiation in Global Warming Policy," Environmental and Resource Economics, Vol. 12, pp. 25-51.

Shukla, P.R. (1999), "Justice, Equity and Efficiency in Climate Change: A Developing Country Perspective," in Ferenc L. Tóth, editor, Fair Weather? Equity Concerns in Climate Change, Earthscan Publications Ltd., London.

Sydney Morning Herald (1999), "Sydney Futures Exchange Expands into Carbon Trading," August 31, 1999.

Tietenberg, Tom, Michael Grubb, Axel Michaelowa, Byron Swift, and ZhongXiang Zhang (1998) "Greenhouse Gas Emissions Trading: Defining the Principles, Modalities, Rules and Guidelines for Verification, Reporting and Accountability," United Nations Conference on Trade and Development (UNCTAD), (http://www.colby.edu/personal/thtieten/UNCTAD.pdf).

Times of London (1999), “Top 25 UK Companies Seek Emissions Trading,” June 28, 1999, (http://www.sundaytimes.co.uk/news/pages/tim/99/06/28/timbizbiz02017.html?2218746).

Torvanger, Asbjørn, and Odd Godal (1999), "A Survey of Differentiation Methods for Greenhouse Gas Reduction Targets," CICERO Report 1999:5, Center for International Climate and Environmental Research, Oslo, (http://www.cicero.uio.no/ ftp/publications/reports/r1999-05.pdf).

UN (1985), "Protocol on the Reduction of Sulphur Emissions or Their Transboundary Fluxes by at Least 30 Per Cent," July 8, 1985, United Nations Document ECE/EB.AIR/12; International Digest of Health Legislation 36 (1985): 799.

UN (1992), United Nations Framework Convention on Climate Change (UNFCCC), UNFCCC Secretariat, Bonn, Germany, (http://www.unfccc.de/resource/conv/index.html).

UN (1997), Kyoto Protocol to the United Nations Framework Convention on Climate Change, UNFCCC Secretariat, Bonn, Germany, (http://www.unfccc.de/resource/docs/convkp/kpeng.html).

UN/ECE (1994), "Protocol to the 1979 Convention on Long-Range Transboundary Air Pollution on Further Reduction of Sulphur Emissions," United Nations Economic Commission for Europe, Environment and Human Settlements Division, Geneva.

Victor, David (1999), “The Regulation of Greenhouse Gases: Does Fairness Matter?” in Ferenc L. Tóth, editor, Fair Weather? Equity Concerns in Climate Change, Earthscan Publications Ltd., London.

Victor, D.G., N. Nakićenović, and N. Victor (1998), "The Kyoto Protocol Carbon Bubble: Implications for Russia, Ukraine, and Emission Trading," IR-98-094, International Institute for Applied Systems Analysis, Laxenburg, Austria, (www.iiasa.ac.at/Publications/Documents/IR-98-094.pdf).

von Weizsäcker, Ernst, Amory B. Lovins, and L. Hunter Lovins (1997), Factor Four: Doubling Wealth, Halving Resource Use, Earthscan Publications Ltd., London. 
Wigley, T.R., R. Richels, and J. Edmonds (1996), "Economic and Environmental Choices in the Stabilization of Atmospheric $\mathrm{CO}_{2}$ Concentrations," Nature, 359(6562), 240-243.

Young, H. Peyton (1994), Equity: In Theory and Practice, Princeton University Press, Princeton, NJ, USA. 